\title{
COVID-19 and diabetes mellitus: from pathophysiology to clinical management
}

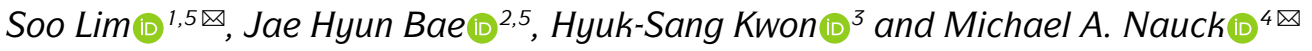

Abstract | Initial studies found increased severity of coronavirus disease 2019 (COVID-19), caused by infection with severe acute respiratory syndrome coronavirus 2 (SARS-CoV-2), in patients with diabetes mellitus. Furthermore, COVID-19 might also predispose infected individuals to hyperglycaemia. Interacting with other risk factors, hyperglycaemia might modulate immune and inflammatory responses, thus predisposing patients to severe COVID-19 and possible lethal outcomes. Angiotensin-converting enzyme 2 (ACE2), which is part of the renin-angiotensin-aldosterone system (RAAS), is the main entry receptor for SARS-CoV-2; although dipeptidyl peptidase 4 (DPP4) might also act as a binding target. Preliminary data, however, do not suggest a notable effect of glucose-lowering DPP4 inhibitors on SARS-CoV-2 susceptibility. Owing to their pharmacological characteristics, sodium-glucose cotransporter 2 (SGLT2) inhibitors might cause adverse effects in patients with COVID-19 and so cannot be recommended. Currently, insulin should be the main approach to the control of acute glycaemia. Most available evidence does not distinguish between the major types of diabetes mellitus and is related to type 2 diabetes mellitus owing to its high prevalence. However, some limited evidence is now available on type 1 diabetes mellitus and COVID-19. Most of these conclusions are preliminary, and further investigation of the optimal management in patients with diabetes mellitus is warranted.

Severe acute respiratory syndrome coronavirus 2 (SARS-CoV-2), the novel coronavirus that causes coronavirus disease 2019 (COVID-19), was first reported in Wuhan, China, in December 2019 and has spread worldwide. As of 29 October 2020, 44,351,506 globally confirmed cases of COVID-19 have been reported on the World Health Organization COVID-19 dashboard, including 1,171,255 deaths. The fatality rate for COVID-19 has been estimated to be $0.5-1.0 \%{ }^{1-3}$. From 1 March to 30 May 2020, 122,300 excess all-cause deaths occurred in the USA, of which 95,235 (79\%) were officially attributed to COVID-19 (REF. ${ }^{4}$ ). Of note, mortality from COVID-19 and seasonal influenza is not equivalent, as deaths associated with these diseases do not reflect frontline clinical conditions in the same way. For example, COVID-19 pandemic-hit areas have been facing critical shortages in terms of access to supplies such as ventilators and intensive care unit (ICU) facilities ${ }^{5}$.

SARS-CoV-2 is a positive-stranded RNA virus that is enclosed by a protein-decorated lipid bilayer containing a single-stranded RNA genome; SARS-CoV-2 has $82 \%$ homology with human SARS-CoV, which causes severe acute respiratory syndrome $(\mathrm{SARS})^{6}$. In human cells, the main entry receptor for SARS-CoV-2 is angiotensin-converting enzyme $2(\mathrm{ACE} 2)^{7}$, which is highly expressed in lung alveolar cells, cardiac myocytes, vascular endothelium and various other cell types ${ }^{8}$. In humans, the main route of SARS-CoV-2 transmission is through virus-bearing respiratory droplets ${ }^{9}$. Generally, patients with COVID-19 develop symptoms at 5-6 days after infection. Similar to SARS-CoV and the related Middle Eastern respiratory syndrome (MERS)-CoV, SARS-CoV-2 infection induces mild symptoms in the initial stage for 2 weeks on average but has the potential to develop into severe illness, including a systemic inflammatory response syndrome, acute respiratory distress syndrome (ARDS), multi-organ involvement and shock ${ }^{10}$. Patients at high risk of severe COVID-19 or death have several characteristics, including advanced age and male sex, and have underlying health issues, such as cardiovascular disease (CVD), obesity and/or type 1 diabetes mellitus (T1DM) or type 2 diabetes mellitus (T2DM) $)^{11-13}$. A few early studies have shown that underlying CVD and diabetes mellitus are common among patients with COVID-19 admitted to ICUs $^{14,15}$. T2DM is typically a disease of advanced age, 


\section{Key points}

- Underlying diabetes mellitus and cardiovascular diseases are considered risk factors for increased coronavirus disease 2019 (COVID-19) disease severity and worse outcomes, including higher mortality.

- Potential pathogenetic links between COVID-19 and diabetes mellitus include effects on glucose homeostasis, inflammation, altered immune status and activation of the renin-angiotensin-aldosterone system (RAAS).

- During the COVID-19 pandemic, tight control of glucose levels and prevention of diabetes complications might be crucial in patients with diabetes mellitus to keep susceptibility low and to prevent severe courses of COVID-19.

- Evidence suggests that insulin and dipeptidyl peptidase 4 inhibitors can be used safely in patients with diabetes mellitus and COVID-19; metformin and sodiumglucose cotransporter 2 inhibitors might need to be withdrawn in patients at high risk of severe disease.

- Pharmacological agents under investigation for the treatment of COVID-19 can affect glucose metabolism, particularly in patients with diabetes mellitus; therefore, frequent blood glucose monitoring and personalized adjustment of medications are required.

- As COVID-19 lacks definitive treatment so far, patients with diabetes mellitus should follow general preventive rules strictly and monitor glucose levels more frequently, engage in physical activity, eat healthily and control other risk factors.

Cytokine storm

An uncontrolled excessive

production of markers of

inflammation, followed by an

abnormal inflammatory

response, which results from

the effects of a combination of pro-inflammatory

immunoactive molecules, such as interleukins, interferons, chemokines and tumour necrosis factor. and, therefore, whether diabetes mellitus is a COVID19 risk factor over and above advanced age is currently unknown.

The basic and clinical science of the potential inter-relationships between diabetes mellitus and COVID-19 has been reviewed ${ }^{16}$. However, knowledge in this field is emerging rapidly, with numerous publications appearing frequently. This Review summarizes the new advances in diabetes mellitus and COVID-19 and extends the focus towards clinical recommendations for patients with diabetes mellitus at risk of or affected by COVID-19. Most available research does not distinguish between diabetes mellitus type and is mainly focused on T2DM, owing to its high prevalence. However, some limited research is available on COVID-19 and T1DM, which we highlight in this Review.

\section{Potential mechanisms}

The presence of diabetes mellitus and the individual degree of hyperglycaemia seem to be independently associated with COVID-19 severity and increased mortality ${ }^{11,12,17,18}$. Furthermore, the presence of typical complications of diabetes mellitus (CVD, heart failure and chronic kidney disease) increases COVID-19 mortality ${ }^{11,19}$. We propose some pathophysiological mechanisms leading to increased cardiovascular and all-cause mortality after infection with SARS-CoV-2 in patients with diabetes mellitus (FIG. 1).

\footnotetext{
Author addresses

${ }^{1}$ Department of Internal Medicine, Seoul National University Bundang Hospital, Seoul National University College of Medicine, Seongnam, South Korea.

${ }^{2}$ Department of Internal Medicine, Korea University Anam Hospital, Korea University College of Medicine, Seoul, South Korea.

${ }^{3}$ Department of Internal Medicine, Yeouido St Mary's Hospital, The Catholic University of Korea, Seoul, South Korea.

${ }^{4}$ Diabetes Division, Katholisches Klinikum Bochum, St Josef-Hospital (Ruhr-Universität Bochum), Bochum, Germany.

${ }^{5}$ These authors contributed equally to this work: Soo Lim, Jae Hyun Bae.
}

COVID-19 and glucose metabolism. In human monocytes, elevated glucose levels directly increase SARS-CoV-2 replication, and glycolysis sustains SARS-CoV-2 replication via the production of mitochondrial reactive oxygen species and activation of hypoxia-inducible factor $1 \alpha^{20}$. Therefore, hyperglycaemia might support viral proliferation. In accord with this assumption, hyperglycaemia or a history of T1DM and T2DM were found to be independent predictors of morbidity and mortality in patients with SARS $^{21}$. Furthermore, comorbid T2DM in mice infected with MERS-CoV resulted in a dysregulated immune response, leading to severe and extensive lung pathology $y^{22}$. Patients with diabetes mellitus typically fall into higher categories of SARS-CoV-2 infection severity than those without ${ }^{23,24}$, and poor glycaemic control predicts an increased need for medications and hospitalizations, and increased mortality ${ }^{18,25}$ (TABLE 1; Supplementary Table 1).

Of note, glycaemic deterioration is a typical complication of COVID-19 in patients with impaired glucose regulation or diabetes mellitus. For example, in patients requiring insulin, SARS-CoV infection was associated with a rapidly increasing need for high doses of insulin (often approaching or exceeding $100 \mathrm{IU}$ per day) ${ }^{26}$. Changes in insulin needs are seemingly associated with the levels of inflammatory cytokines ${ }^{26,27}$. Although ketoacidosis is typically a problem closely associated with T1DM, in patients with COVID-19, ketoacidosis can also occur in those with T2DM. For example, in a systematic review, $77 \%$ of patients with COVID-19 who developed ketoacidosis had T2DM ${ }^{28}$.

Inflammation and insulin resistance. The most common post-mortem findings in the lungs of people with fatal COVID-19 are diffuse alveolar damage and inflammatory cell infiltration with prominent hyaline membranes $^{29}$. Other critical findings include myocardial inflammation, lymphocyte infiltration in the liver, macrophage clustering in the brain, axonal injuries, microthrombi in glomeruli and focal pancreatitis ${ }^{29}$. These findings indicate an inflammatory pathology in COVID-19 (FIG. 1). In addition, an integrated analysis showed that patients with severe COVID-19 have a highly impaired interferon type I response with low IFNa activity in the blood, indicating high blood viral load, and an impaired inflammatory response ${ }^{30}$. It has also been reported that the inborn errors of type I interferon immunity related to TLR3 and IRF7 (REF. ${ }^{31}$ ), or B cell immunity ${ }^{32}$, underlie fatal COVID-19 pneumonia in $12.5 \%$ of men and $2.6 \%$ of women. The aforementioned findings indicate considerable variations in immune phenotypes among patients with COVID-19.

Some patients with severe COVID-19 experience a cytokine storm, which is a dangerous and potentially life-threatening event ${ }^{33,34}$. A retrospective study of 317 patients with laboratory-confirmed COVID-19 showed the presence of active inflammatory responses (IL-6 and lactate dehydrogenase) within $24 \mathrm{~h}$ of hospital admission, which were correlated with disease severity ${ }^{35}$. Furthermore, blood levels of IL- 6 and lactate dehydrogenase are independent predictors of COVID-19 


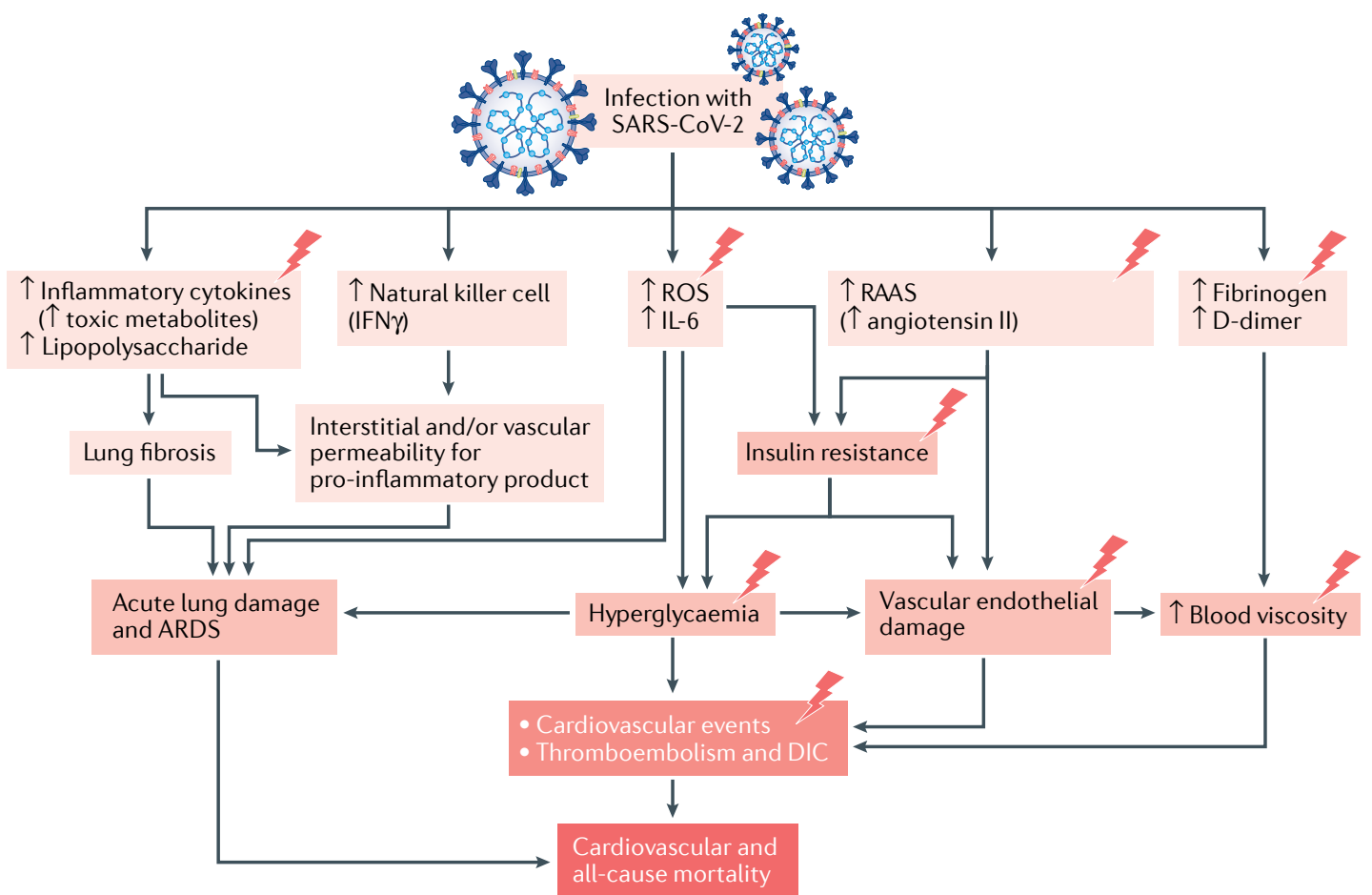

Fig. 1 | Potential pathogenic mechanisms in patients with T2DM and COVID-19. Lightning bolts indicate mechanisms that are accentuated in patients with type 2 diabetes mellitus (T2DM). Infection with severe acute respiratory syndrome coronavirus 2 (SARS-CoV-2) ${ }^{7,239}$ can lead to increased levels of inflammatory mediators in the blood, including lipopolysaccharide $^{240,241}$, inflammatory cytokines ${ }^{9,43,242,243}$ and toxic metabolites. Modulation of natural killer cell activity (increased ${ }^{9,39,50}$ or decreased ${ }^{242,244}$ ) and IFN $\gamma$ production can increase the interstitial and/or vascular permeability for pro-inflammatory products $^{243,245,246}$. In addition, infection with SARS-CoV-2 leads to increased reactive oxygen species (ROS) production ${ }^{243,247,248}$. These effects lead to lung fibrosis ${ }^{249}$, acute lung damage and acute respiratory distress syndrome (ARDS) ${ }^{9,250}$. ROS production and viral activation of the renin-angiotensin-aldosterone system (RAAS) ${ }^{249,251}$ (via increased angiotensin Il expression) cause insulin resistance $\mathrm{e}^{39,252}$, hyperglycaemia ${ }^{253}$ and vascular endothelial damage ${ }^{243,254,255}$, all of which contribute to cardiovascular events, thromboembolism and disseminated intravascular coagulation (DIC). Infection also causes increases in the clotting components fibrinogen ${ }^{60,256}$ and D-dimer ${ }^{43,242,257}$, leading to increases in blood viscosity ${ }^{146,243}$ and vascular endothelial damage, and associated cardiovascular events, thromboembolism and DIC. COVID-19, coronavirus disease 2019.

severity ${ }^{35}$. Of note, IL-6 has pro-inflammatory properties in innate immunity, and its levels can correlate with both the degree of disease severity and with a procoagulant profile ${ }^{36}$. Through increasing oxidative stress, IL-6 can damage proteins, lipids and DNA, and impair the body's structure and function, and we propose that this effect might lead to rapid progression of COVID-19 in patients with diabetes mellitus (FIG. 1). Notably, a systems biological assessment of immunity in patients with severe COVID-19 showed increased levels of bacterial DNA and lipopolysaccharide in the plasma ${ }^{37}$, which were positively correlated with the plasma levels of IL- 6 as well as EN-RAGE, a biomarker of pulmonary injury that is implicated in the pathogenesis of sepsis-induced ARDS ${ }^{38}$. These findings suggest a role for bacterial products, perhaps of lung origin, in augmenting the production of inflammatory cytokines in severe COVID-19.

Several mechanisms have been proposed by which virally induced inflammation increases insulin resistance ${ }^{39}$. For example, in coronavirus-induced pneumonia, such as SARS and MERS, inflammatory cells infiltrate the lungs, leading to acute lung injury, ARDS and/or death ${ }^{40}$. This large burden of inflammatory cells can affect the functions of skeletal muscle and the liver, the major insulin-responsive organs that are responsible for the bulk of insulin-mediated glucose uptake $^{41}$. In addition, patients with severe COVID-19 show muscle weakness and elevation of liver enzyme activities, which might suggest multiple organ failure, particularly during a cytokine storm ${ }^{42}$.

COVID-19 can progress to ARDS, which requires positive pressure oxygen and intensive care therapy ${ }^{9}$. ARDS is characterized by severe oedema of the alveolar wall and lung parenchyma, accompanied by a marked rise in inflammatory parameters, such as C-reactive protein levels and erythrocyte sedimentation rates. Patients with COVID-19 also exhibit elevation of other inflammatory markers, such as D-dimer, ferritin and IL-6 (REF. ${ }^{43}$ ), which might contribute to an increased risk of microvascular and macrovascular complications originating from low-grade vascular inflammation in patients with underlying diabetes mellitus ${ }^{44}$. In a nationwide study in France, microvascular and macrovascular complications of diabetes mellitus were significantly associated with increased risk of mortality in patients with COVID-19 (REF. ${ }^{45}$ ). Whether COVID-19 accelerates the progression of diabetic complications needs to be studied. Thus, the molecular pathogenesis of SARS-CoV-2 is related to oxidative stress and inflammation, which can contribute to sepsis progression (FIG. 1). 
Table 1 | Clinical characteristics and outcomes in patients with diabetes mellitus and COVID-19

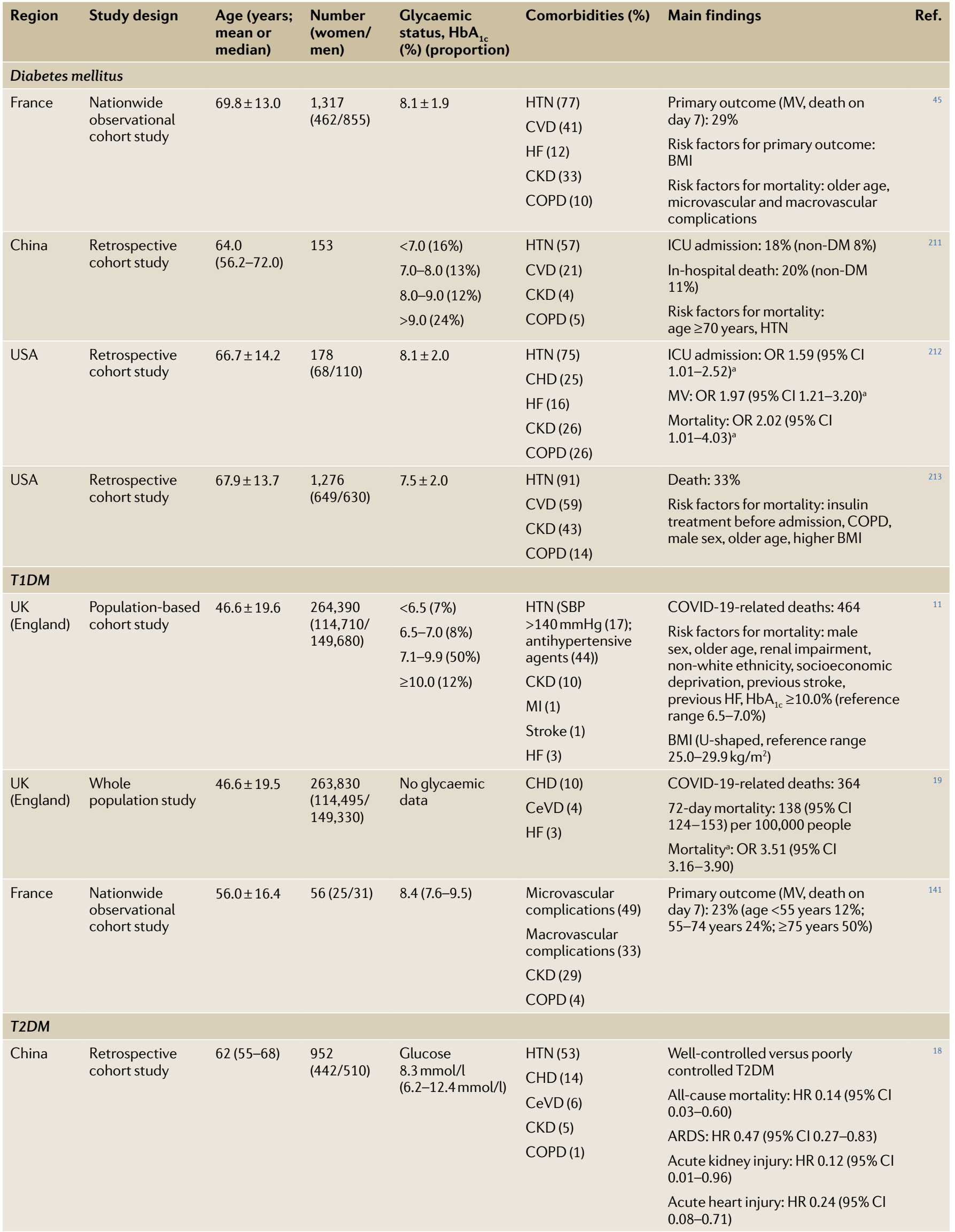


Table 1 (cont.) | Clinical characteristics and outcomes in patients with diabetes mellitus and COVID-19

\begin{tabular}{|c|c|c|c|c|c|c|c|}
\hline Region & Study design & $\begin{array}{l}\text { Age (years; } \\
\text { mean or } \\
\text { median) }\end{array}$ & $\begin{array}{l}\text { Number } \\
\text { (women/ } \\
\text { men) }\end{array}$ & $\begin{array}{l}\text { Glycaemic } \\
\text { status, } \mathrm{HbA}_{1 \mathrm{c}} \\
\text { (\%) (proportion) }\end{array}$ & Comorbidities (\%) & Main findings & Ref. \\
\hline \multicolumn{8}{|c|}{ T2DM (cont.) } \\
\hline $\begin{array}{l}\text { UK } \\
\text { (England) }\end{array}$ & $\begin{array}{l}\text { Population-based } \\
\text { cohort study }\end{array}$ & $67.5 \pm 13.4$ & $\begin{array}{l}2,874,020 \\
(1,267,590 / \\
1,606,430)\end{array}$ & $\begin{array}{l}<6.5(25 \%) \\
6.5-7.0(21 \%) \\
7.1-7.5(13 \%) \\
7.6-9.9(25 \%) \\
\geq 10.0(11 \%)\end{array}$ & $\begin{array}{l}\text { HTN (SBP } \\
>140 \mathrm{mmHg}(67) \text {; } \\
\text { antihypertensive } \\
\text { agents (76)) } \\
\text { CKD (18) } \\
\text { MI (2) } \\
\text { stroke (2) } \\
\text { HF (5) }\end{array}$ & $\begin{array}{l}\text { COVID-19-related deaths: } 10,525 \\
\text { Risk factors for mortality: male } \\
\text { sex, older age, renal impairment, } \\
\text { non-white ethnicity, socioeconomic } \\
\text { deprivation, previous stroke, } \\
\text { previous } \mathrm{HF}, \mathrm{HbA}_{1 \mathrm{c}} \geq 7.5 \% \text { or }<6.5 \% \\
\text { (reference range } 6.5 \%-7.0 \% \text { ), } \\
\text { BMI (U-shaped, reference range } \\
25.0-29.9 \mathrm{~kg} / \mathrm{m}^{2} \text { ) }\end{array}$ & \\
\hline $\begin{array}{l}\text { UK } \\
\text { (England) }\end{array}$ & $\begin{array}{l}\text { Whole } \\
\text { population study }\end{array}$ & $67.4 \pm 13.4$ & $\begin{array}{l}2,864,670 \\
(1,263,615 / \\
1,601,045)\end{array}$ & $\begin{array}{l}\text { No glycaemic } \\
\text { data }\end{array}$ & $\begin{array}{l}\mathrm{CHD}(19) \\
\mathrm{CeVD}(7) \\
\mathrm{HF}(6)\end{array}$ & $\begin{array}{l}\text { COVID-19-related deaths: 7,434 } \\
\text { 72-day mortality: } 260 \text { (95\% CI } \\
\text { 254-264) per 100,000 people } \\
\text { Mortality }: \text { OR } 2.03 \text { ( } 95 \% \text { Cl 1.97-2.09) }\end{array}$ & 19 \\
\hline China & $\begin{array}{l}\text { Retrospective } \\
\text { cohort study }\end{array}$ & $\begin{array}{l}63.0 \\
(56.0-69.0)\end{array}$ & $\begin{array}{l}1,213 \\
(632 / 581)\end{array}$ & $\begin{array}{l}\text { Glucose } 8.6 \\
(6.5-12.5) \mathrm{mmol} / \mathrm{l}\end{array}$ & $\begin{array}{l}\mathrm{CHD}(15) \\
\mathrm{HF}(0.2) \\
\operatorname{CeVD}(4)\end{array}$ & $\begin{array}{l}\text { Metformin versus non-metformin } \\
\text { Acidosis: HR } 2.73 \text { (95\% Cl 1.04-7.13) } \\
\text { Lactic acidosis: HR 4.46 (95\% Cl } \\
\text { 1.11-18.00) } \\
\text { Mortality: HR 1.65 (95\% Cl 0.71-3.86) } \\
\text { ARDS: HR 0.85 (95\% Cl 0.61-1.17) } \\
\text { DIC: HR 1.68 (95\% Cl 0.26-10.90) } \\
\text { Acute kidney injury: HR 0.65 (95\% Cl } \\
\text { 0.19-2.24) } \\
\text { Acute heart injury: HR } 1.02 \text { (95\% Cl } \\
0.62-1.66)\end{array}$ & 214 \\
\hline
\end{tabular}

Immunomodulation. It is recognized that mechanisms linking COVID-19 and both T1DM and T2DM overlap with pathways that regulate immune function ${ }^{16}$. For example, age is the strongest risk factor for developing T2DM and the effect of ageing on immune function might be equally important for COVID-19 susceptibility and severity. Hyperglycaemia can affect immune function; conversely, a dysregulated immunological status is linked to macrovascular complications of diabetes mellitus ${ }^{46,47}$. Thus, T2DM is associated with immunological dysregulation, which is potentially equivalent to accelerated ageing, and could therefore potentially explain the poor prognosis in patients with diabetes mellitus and COVID-19 (FIG. 1).

In individuals with obesity, pro-inflammatory cytokines with a T helper type 1 cell signature are known to increase insulin resistance ${ }^{48}$; however, the role of such cytokines in COVID-19 is unclear. Whether and how SARS-CoV-2 infection induces loss of glycaemic control in patients who are at risk of developing diabetes mellitus is also unclear. One study demonstrated that acute respiratory virus infection increases IFN $\gamma$ production, and it causes muscle insulin resistance in humans, which drives compensatory hyperinsulinaemia to maintain euglycaemia and to boost antiviral $\mathrm{CD}^{+} \mathrm{T}$ cell responses ${ }^{39}$. It can be hypothesized that in patients with impaired glucose tolerance or diabetes mellitus, such compensation might fail ${ }^{49}$. Of note, hyperinsulinaemia can increase antiviral immunity through direct stimulation of $\mathrm{CD}^{+}$effector $\mathrm{T}$ cell function ${ }^{39}$. In prediabetic mice with hepatic insulin resistance caused by diet-induced obesity, murine cytomegalovirus infection resulted in a deterioration of glycaemic control ${ }^{39}$. Thus, during SARS-CoV-2 infection, the ensuing antiviral immune and inflammatory responses can change insulin sensitivity, potentially aggravating impairments of glucose metabolism (FIG. 1).

Interestingly, respiratory syncytial viruses increase the production of IFN $\gamma$, which activates natural killer (NK) cells as a defensive mechanism ${ }^{50}$. Both increased production of IFN $\gamma$ and activated NK cells exacerbate systemic inflammation in muscle and adipose tissues, overall establishing a detrimental effect on glucose uptake ${ }^{51}$. Furthermore, a relationship exists between NK cell activity and glucose control in patients with impaired glucose metabolism. For example, NK cell activity was lower in patients with T2DM than in those with prediabetes or normal glucose tolerance ${ }^{52}$. In addition, multiple regression analysis showed that the $\mathrm{HbA}_{1 \mathrm{c}}$ level is an independent predictor of NK cell activity in patients with $\mathrm{T} 2 \mathrm{DM}^{52}$. Thus, individuals with impaired glucose tolerance or diabetes mellitus have reduced NK cell activity, which might help to explain why patients with diabetes mellitus are more susceptible to COVID-19 


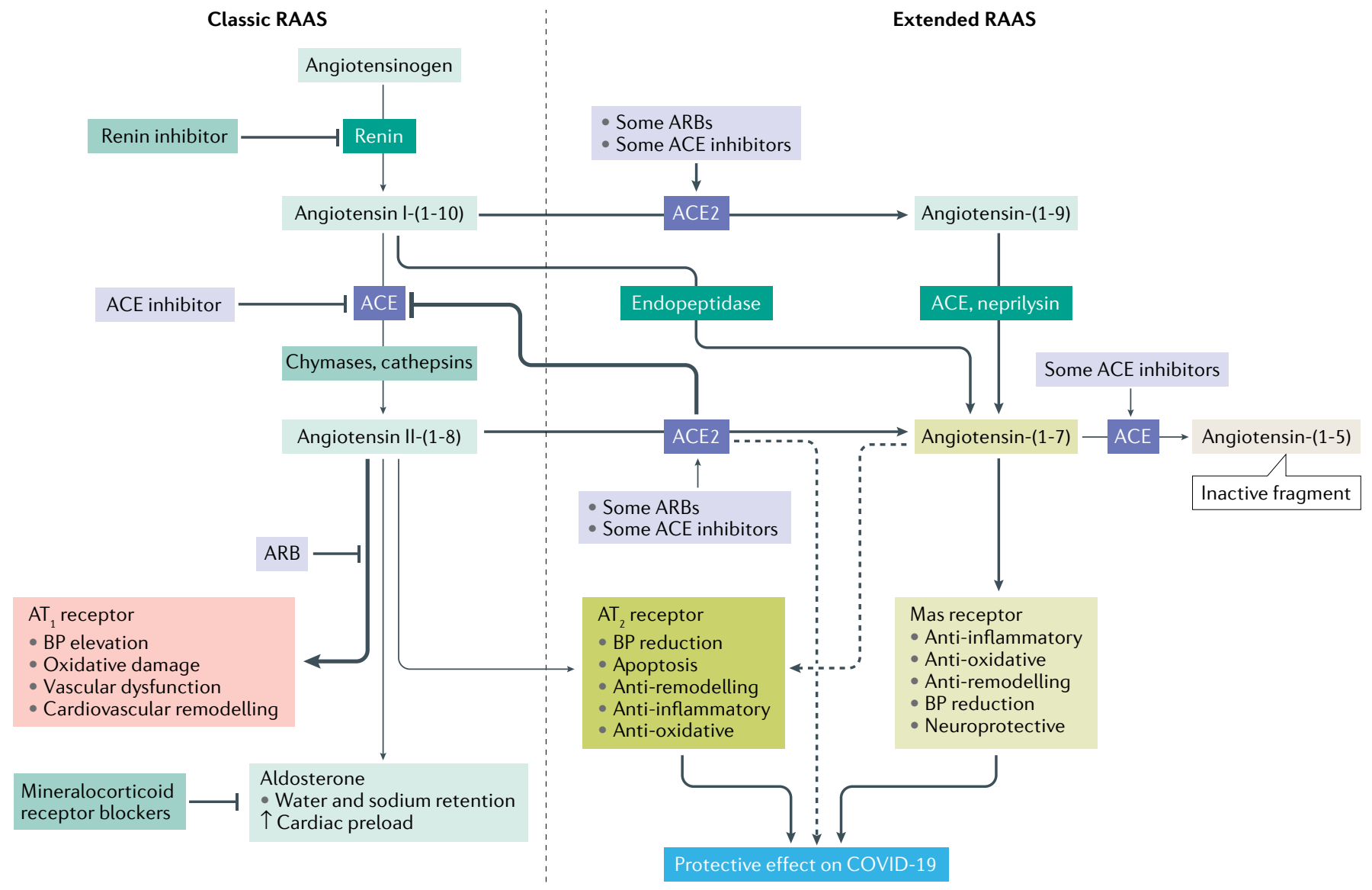

Renin-angiotensinaldosterone system (RAAS). A hormone system that regulates blood pressure and fluid and electrolyte balance, as well as systemic vascular resistance.

Fig. 2 | The role of ACE2 within the RAAS. Because angiotensin-converting enzyme 2 (ACE2) is considered an important severe acute respiratory syndrome coronavirus 2 (SARS-CoV-2) receptor facilitating infection of relevant cells, such as pneumocytes, it is important to understand its normal physiological function. Inhibition of ACE blocks metabolism of angiotensin-(1-7) to angiotensin-(1-5) and can lead to elevation of angiotensin-(1-7) levels in plasma and tissues ${ }^{258}$. In animal models, angiotensin-(1-7) enhances vasodilation and inhibits vascular contractions to angiotensin $1 I^{258}$. An ex vivo study using human internal mammary arteries showed that angiotensin-(1-7) blocks angiotensin Il-induced vasoconstriction and inhibits ACE in human cardiovascular tissues ${ }^{258}$. In an ex vivo study, angiotensin-(1-7) and some ACE inhibitors, such as quinaprilat and captopril, potentiated bradykinin, resulting in blood pressure reduction by inhibiting $A C E^{259}$. Thus, angiotensin(1-7) acts as an ACE inhibitor and might stimulate bradykinin release ${ }^{259}$. These results show that angiotensin-(1-7) might be an important modulator of the human renin-angiotensin-aldosterone system (RAAS). ARB, angiotensin receptor blocker; $\mathrm{AT}_{1}$, angiotensin type $1 ; \mathrm{AT}_{2}$, angiotensin type 2 ; $\mathrm{BP}$, blood pressure.

and have a worse prognosis than those without diabetes mellitus. In summary, understanding the immunomodulation occurring during SARS-CoV-2 infection is crucial for identifying therapeutic targets and developing effective medications as well as understanding its pathogenesis.

Renin-angiotensin-aldosterone system. As a part of the renin-angiotensin-aldosterone system (RAAS) (FIG. 1), ACE2 has already received much attention as it can also serve as an entry receptor for SARS-CoV as well as SARS-CoV-2 (REF. $\left.{ }^{53}\right)$. ACE2 was initially reported to be predominantly expressed in the respiratory system ${ }^{53}$. However, a more sophisticated study using immunohistochemical analyses found that ACE2 is expressed mainly in the intestines, kidneys, myocardium, vasculature and pancreas, but expression is limited in the respiratory system ${ }^{54}$. Evidence therefore suggests that ACE2 is expressed in many human cells and tissues, including pancreatic islets ${ }^{55}$. Studies using samples from patients with COVID-19 are warranted to investigate the colocalization of SARS-CoV-2 and ACE2 and help in understanding the progression of COVID-19 and the viral pathogenesis of SARS-CoV-2.

Some evidence suggests an association between ACE2 and glucose regulation. For example, Ace2-knockout mice have been found to be more susceptible than wild-type mice to high-fat diet-induced pancreatic $\beta$-cell dysfunction ${ }^{56}$. Furthermore, infection with SARS-CoV can cause hyperglycaemia in people without pre-existing diabetes mellitus ${ }^{57}$. This finding and the localization of ACE2 expression in the endocrine pancreas together suggest that coronaviruses might specifically damages islets, potentially leading to hyperglycaemia ${ }^{57}$. Of note, hyperglycaemia was seen to persist for 3 years after recovery from SARS, perhaps indicating long-term damage to pancreatic $\beta$-cells ${ }^{57}$. These data suggest that the ACE2 as part of the RAAS might be involved in the association between COVID-19 and diabetes mellitus (FIG. 2). 


\section{Increased COVID-19 severity}

Two early case series of critically ill patients with COVID-19 admitted to ICUs in the USA found diabetes mellitus prevalence of $58 \%$ and $33 \%{ }^{58,59}$, suggesting a link between severe COVID-19 and diabetes mellitus. Several mechanisms are thought to be responsible for an accentuated clinical severity of COVID-19 in people with diabetes mellitus (FIC. 3). As described already, glucotoxicity, endothelial damage by inflammation, oxidative stress and cytokine production contribute to an increased risk of thromboembolic complications and of damage to vital organs in patients with diabetes mellitus ${ }^{60}$ (FIG. 1). In addition, drugs often used in the clinical care of patients with COVID-19, such as systemic corticosteroids or antiviral agents, might contribute to worsening hyperglycaemia (TABLE 2; Supplementary Table 2).

A multicentre retrospective study from China found that high fasting glucose levels ( $\geq 7.0 \mathrm{mmol} / \mathrm{l}(\geq 126 \mathrm{mg} / \mathrm{dl})$ ) at admission was an independent predictor of increased mortality in patients with COVID-19 who did not have diabetes mellitus ${ }^{61}$. Therefore, it is prudent to monitor glucose levels and to treat worsening hyperglycaemia in patients with progression to severe states of COVID-19.

Of note, a study found that therapy with the corticosteroid dexamethasone reduced mortality in patients receiving invasive mechanical ventilation by $36 \%$ (HR 0.64, 95\% CI 0.51-0.81) and in those receiving oxygen only by $18 \%$ (HR 0.82 ; $95 \%$ CI $0.72-0.94)^{62}$. Whether similar benefits were observed in the $24 \%$ of participants with diabetes mellitus has not yet been reported. Glucocorticoid therapy probably reduces production of cytokines and prevents their detrimental effects in patients with severe COVID-19. Further long-term studies are required to confirm this result, particularly in patients with diabetes mellitus.

\section{Glucose-lowering drugs}

Glucose-lowering medications commonly used to treat diabetes mellitus might have effects on COVID-19 pathogenesis, and these effects could have implications

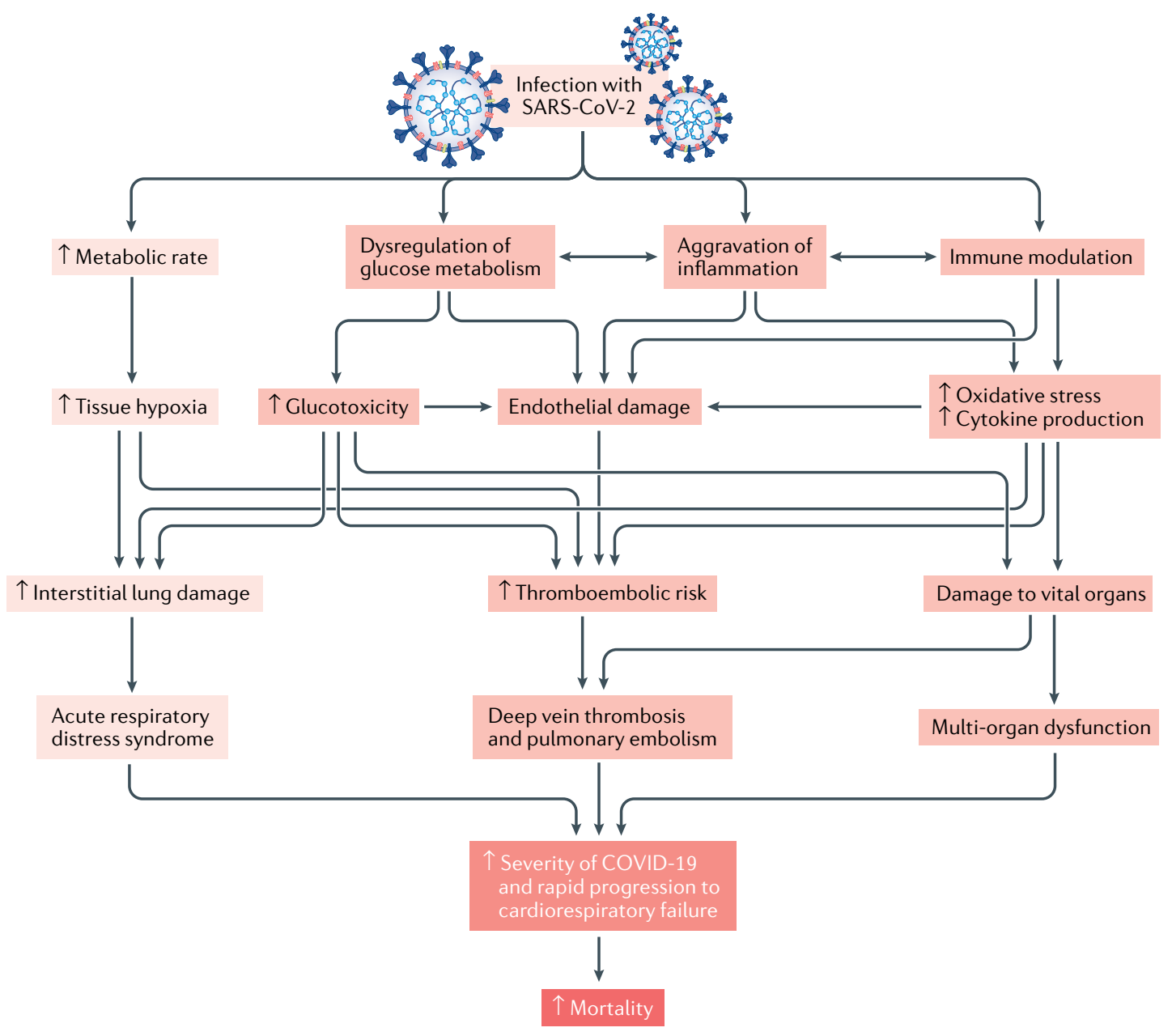

Fig. 3 | Potential accentuated clinical processes after SARS-CoV-2 infection in people with diabetes mellitus. Darker red indicates processes that are accentuated in patients with type 2 diabetes mellitus (T2DM). Severe acute respiratory syndrome coronavirus 2 (SARS-CoV-2) infection increases metabolic rate, resulting in tissue hypoxia, which induces interstitial lung damage and acute respiratory distress syndrome ${ }^{9,250}$. Patients with diabetes mellitus and coronavirus disease 2019 (COVID-19) exhibit dysregulation of glucose homeostasis, aggravation of inflammation and impairment in the function of the immune system ${ }^{9,43,242,243}$. These conditions increase oxidative stress ${ }^{243,247,248}$, cytokine production and endothelial dysfunction ${ }^{243,254,255}$, leading to increased risk of thromboembolism and damage to vital organs. All these factors contribute to increased severity of COVID-19 and rapid progression to cardiorespiratory failure in patients with diabetes mellitus. 
Table 2 | Glycaemic effects of potential pharmacological agents for COVID-19

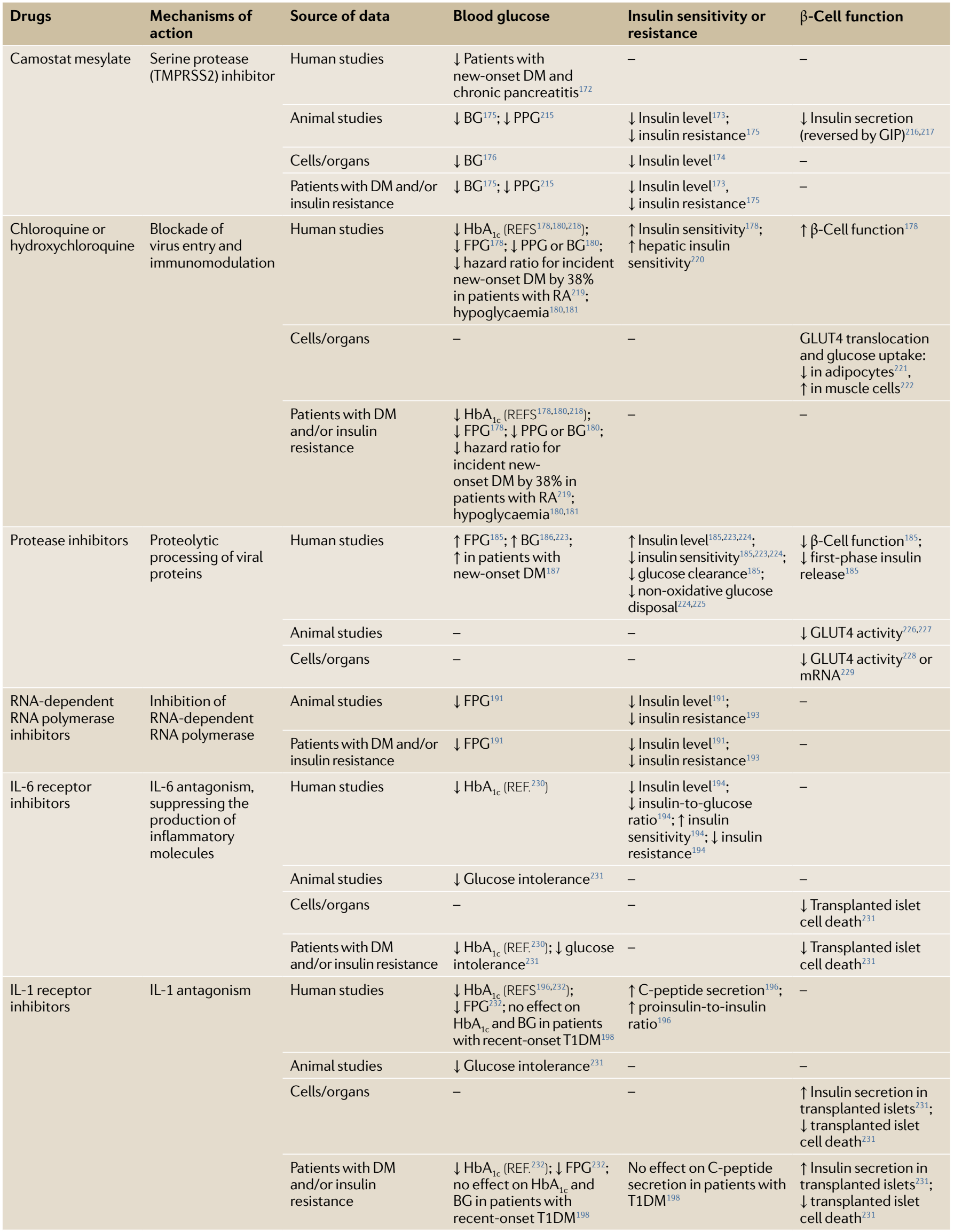


Table 2 (cont.) | Glycaemic effects of potential pharmacological agents for COVID-19

\begin{tabular}{|c|c|c|c|c|c|}
\hline Drugs & $\begin{array}{l}\text { Mechanisms of } \\
\text { action }\end{array}$ & Source of data & Blood glucose & $\begin{array}{l}\text { Insulin sensitivity or } \\
\text { resistance }\end{array}$ & $\beta$-Cell function \\
\hline \multirow[t]{2}{*}{ IL-1 $\beta$ inhibitors } & \multirow[t]{2}{*}{ IL-1 $\beta$ antagonism } & Human studies & $\begin{array}{l}\text { No effect on } \mathrm{HbA}_{1 c} \\
\text { in patients with } \\
\text { recent-onset T1DM } 198\end{array}$ & $\begin{array}{l}\text { No effect on C-peptide } \\
\text { secretion in patients } \\
\text { with recent-onset } \\
\text { T1DM }^{198}\end{array}$ & - \\
\hline & & $\begin{array}{l}\text { Patients with DM } \\
\text { and/or insulin } \\
\text { resistance }\end{array}$ & $\begin{array}{l}\text { No effect on } \mathrm{HbA}_{1 c} \\
\text { in patients with } \\
\text { recent-onset T1DM }{ }^{198}\end{array}$ & $\begin{array}{l}\text { No effect on C-peptide } \\
\text { secretion in patients } \\
\text { with recent-onset } \\
\text { T1DM }^{198}\end{array}$ & - \\
\hline \multirow[t]{2}{*}{$\begin{array}{l}\text { JAK1 and JAK2 } \\
\text { inhibitors }\end{array}$} & \multirow{2}{*}{$\begin{array}{l}\text { Suppressing JAK- } \\
\text { STAT signalling, } \\
\text { inhibition of } \\
\text { clathrin-medicated } \\
\text { endocytosis, } \\
\text { immunosuppression }\end{array}$} & Animal studies & $\begin{array}{l}\downarrow \text { Reversal of new-onset } \\
\text { DM in NOD mice }\end{array}$ & $\downarrow$ Insulin level $\left.\right|^{233}$ & - \\
\hline & & $\begin{array}{l}\text { Patients with DM } \\
\text { and/or insulin } \\
\text { resistance }\end{array}$ & $\downarrow$ DM development ${ }^{200}$ & $\downarrow$ Insulin level $\left.\right|^{233}$ & - \\
\hline \multirow[t]{2}{*}{ TNF inhibitors } & \multirow[t]{2}{*}{ TNF antagonism } & Human studies & $\begin{array}{l}\downarrow \mathrm{FBG}^{205,234,235} ; \downarrow \mathrm{HbA}_{1 \mathrm{c}} \\
\left.\text { (REFS }^{230,235}\right) ; \downarrow \text { patients } \\
\text { with new-onset DM and } \\
\text { RA and psoriasis }{ }^{236}\end{array}$ & $\begin{array}{l}\downarrow \text { Insulin } \\
\text { resistance } \\
\uparrow \text { insulin sensitivity }^{205,237} \text {; }\end{array}$ & $\uparrow \beta$-Cell function ${ }^{205}$ \\
\hline & & $\begin{array}{l}\text { Patients with DM and/or } \\
\text { insulin resistance }\end{array}$ & $\underset{\left(\mathrm{REFS}^{230,235}\right)}{\downarrow \mathrm{FBG}^{205,234,235} ; \downarrow \mathrm{HbA}_{1 \mathrm{c}}}$ & $\begin{array}{l}\downarrow \text { Insulin resistance }{ }^{205} \text {; } \\
\uparrow \text { insulin sensitivity }{ }^{205}\end{array}$ & $\uparrow \beta$-Cell function ${ }^{205}$ \\
\hline Corticosteroids ${ }^{206,238}$ & $\begin{array}{l}\text { Anti-inflammatory } \\
\text { effects }\end{array}$ & Human studies & $\begin{array}{l}\uparrow \mathrm{HbA}_{1 \mathrm{c}} ; \uparrow \mathrm{BG} \text { (mainly } \\
\mathrm{PPG} \text { ) }\end{array}$ & $\begin{array}{l}\uparrow \text { Insulin resistance; } \\
\downarrow \text { insulin sensitivity }\end{array}$ & $\begin{array}{l}\downarrow \text { Insulin production } \\
\text { and secretion }\end{array}$ \\
\hline
\end{tabular}

for the management of patients with diabetes mellitus and COVID-19.

Dipeptidyl peptidase 4. Also known as CD26, dipeptidyl peptidase 4 (DPP4) is well recognized to have an important function in glucose homeostasis ${ }^{63}$. In addition, DPP4 has an integral role in the immune system as a marker of activated $\mathrm{T}$ lymphocytes and a regulator of the expression of many chemokines, including CCL5, CXCL12, CXCL2 (also known as GRO-b) and CXCL11 (also known as I-TAC) ${ }^{64,65}$. DDP4 inhibitors (DPP4is) are commonly used to decrease blood levels of glucose and to treat T2DM.

Based on reports of upper respiratory tract infections, concerns have been raised about an increased risk of viral infections with DPP4 inhibition ${ }^{66}$; however, evidence from clinical trials on the association between the use of DPP4is and the risk of community-acquired pneumonia in patients with T2DM does not confirm an increased risk ${ }^{67}$. Although ACE2 is recognized as the main receptor, DPP4 might also bind to SARS-CoV-2 $\left(R F^{68}{ }^{6}\right)$. Interestingly, certain polymorphisms of the DPP4 protein found in people in Africa were associated with a reduced chance of MERS-CoV infection ${ }^{69}$. However, plasma levels of DPP4 in patients with MERS-CoV were statistically significantly reduced ${ }^{70}$, suggesting a protective role of DPP4. Whether DPP4is affect the function of DPP4 as a viral receptor is a matter of debate.
The expression of DPP4 in the spleen, lung, liver, kidney and some immune cells seems to be altered in patients with $\mathrm{T}_{2} \mathrm{DM}^{71}$. Furthermore, DPP4 is not just a cell membrane protein but is shed into the circulation as soluble DPP4. Of note, levels of soluble DPP4 are increased by DPP4is in mice ${ }^{72}$. Whether soluble DPP4 might have a role as a virus receptor or is protective during SARS-CoV-2 infection is entirely unclear. In an in vitro study, treatment with the DPP4is sitagliptin, vildagliptin or saxagliptin did not block the entry of coronaviruses into cells ${ }^{73}$. More detailed studies are needed to fully characterize the role of DPP4is in patients with COVID-19 and T2DM.

Interactions between DPP4 and the RAAS (including ACE2) have not been studied in detail but seem possible ${ }^{74,75}$. DPP4 and the RAAS are linked genetically and are associated with the risk of SARS-CoV-2 infection and possibly severity of COVID-19, particularly in patients with diabetes mellitus ${ }^{76}$. This link is supported by the findings that DPP4 expression was increased in blood T lymphocytes from patients with T2DM and was correlated with insulin resistance ${ }^{77}$, and upregulation of DPP4 in diabetic animals led to dysregulation of immune responses ${ }^{78}$.

Therapy with DPP4is proved neutral, not superior, in terms of major adverse cardiac events, including stroke, in previous DPP4i cardiovascular outcome trials in patients with $\mathrm{T}_{2} \mathrm{DM}^{79,80}$; however, DPP4 
Brain-derived neurotrophic factor

A member of the neurotrophin family of growth factors, which are related to the canonical nerve growth factor. inhibition has been reported to have beneficial effects on the cardiovascular system, such as reducing oxidative stress and endoplasmic reticulum stress, because of its anti-inflammatory properties ${ }^{63,81}$. More specifically, the receptor binding domain of DPP4 interacts with adenosine deaminase (ADA) in $\mathrm{CD}^{+}$and $\mathrm{CD}^{+}$human $\mathrm{T}_{\text {cells }} \mathrm{s}^{82,83}$. This finding indicates a possible modulation of the host's immune system by SARS-CoV-2, through binding to DPP4 and competing for the ADA recognition site. Thus, the DPP4 receptor binding domain might represent a potential strategy for treating infection by SARS-CoV-2 $\left(\right.$ REF. $\left.^{84}\right)$.

Of note, a study found that systemic DPP4 inhibition with DPP4is increased circulating levels of inflammatory markers in a mouse model fed with regular chow ${ }^{85}$. By contrast, in humans, treatment with a DPP4i decreased DPP4 enzyme activity but did not increase the levels of inflammatory markers ${ }^{85}$. These findings suggest the possibility of dissociation between DPP4 enzyme activity, the use of DPP4i and inflammatory markers in animals and humans. Moreover, DPP4i treatment suppressed $\mathrm{T}$ cell immune responses to the virus in an experiment in human peripheral blood ${ }^{86}$. One human study found that circulating levels of brain-derived neurotrophic factor were decreased by DPP4 inhibition ${ }^{87}$. Clearly, the effect of DPP4 inhibition on T cell function and T cell-mediated inflammatory and immune responses in patients with COVID-19 requires further research.

Current knowledge does not suggest safety issues associated with the use of DPP4is in patients with T2DM and COVID-19 (REFS ${ }^{45,88}$ ). In a retrospective case-control study from northern Italy, sitagliptin treatment during hospitalization was associated with reduced mortality and improved clinical outcomes in such patients ${ }^{89}$. Another Italian case series described the association between DPP4i treatment and a statistically significantly reduced mortality; however, this result was based on only 11 patients (of whom one died) ${ }^{90}$. However, DPP4i treatment was associated with worse outcomes (mortality results were not presented) in 27 patients with T2DM treated with DPP4is than in 49 treated with other glucose-lowering medications ${ }^{87}$. Therefore, prospective randomized clinical trials (RCTs) in diverse populations of patients with T2DM and COVID-19 are necessary to assess the potential survival benefits associated with DPP4 inhibition in patients with COVID-19, which might also extend to patients without diabetes mellitus.

Glucagon-like peptide 1 and its analogues. Therapy with most glucagon-like peptide 1 (GLP1) analogues in patients with T2DM reduced the rate of major adverse cardiac events in cardiovascular outcome trials ${ }^{79,91}$. GLP1 contributes to glucose homeostasis and GLP1 receptor stimulation elicits a variety of pleiotropic effects (for example, on immune function ${ }^{92}$ and inflammatory processes $^{93}$ ). In humans, GLP1 receptors are widely distributed in various cells and organs, including the kidneys, lungs, heart, endothelial cells and nerve cells ${ }^{91}$. GLP1-based treatments reduce the production of various inflammatory cytokines and infiltration of immune cells in the liver, kidney, lung, brain and the cardiovascular system $^{63,91,94}$.
In animal models of atherosclerosis, the GLP1 analogue exendin 4 substantially reduced the accumulation of monocytes and macrophages in the vascular wall and inhibited atherogenesis by regulating inflammation in macrophages ${ }^{95}$. In addition, exendin 4 exerted renoprotective effects in animal models through inhibition of nuclear factor- $\kappa \mathrm{B}(\mathrm{NF}-\kappa \mathrm{B})$ activity in the kidney, and elevated NF- $\kappa B$ activity is known to contribute to the crosstalk between inflammation and oxidative stress ${ }^{96}$. In vitro, liraglutide treatment reduced expression of the vascular cell adhesion molecule 1 in human aortic endothelial cells after stimulation with lipopolysaccharide or tumour necrosis factor ${ }^{97}$. In addition, liraglutide administered to C57BL/6 mice fed a high-fat diet reduced inflammation and lipid accumulation in the heart ${ }^{98}$.

Infusions of native GLP1 in patients with T1DM reduced plasma levels of IL-6, intercellular adhesion molecule 1 and markers of oxidative stress ${ }^{99}$. In humans, GLP1 and GLP1 analogues have been shown to be beneficial for the treatment of chronic inflammatory diseases, such as non-alcoholic fatty liver disease, atherosclerosis and neurodegenerative disorders ${ }^{100,101}$ and these effects seem to be primarily mediated by a reduction in the activity of inflammatory pathways ${ }^{91}$. Whether such effects on the low-grade inflammation associated with atherosclerosis translate into anti-inflammatory effects relevant for the disease process of COVID-19 remains to be studied. However, there is little concern for the continued use of GLP1 analogues in patients with diabetes mellitus and COVID-19 based on such properties.

People with CVD or kidney disease show a worse prognosis during the course of COVID-19 than those without these diseases ${ }^{43}$. Therefore, it seems to be prudent to preserve the integrity of the cardiorenal system in people at high risk of SARS-CoV-2 infection. Given that beneficial roles of GLP1 analogues for the prevention of CVD and kidney disease have been well established ${ }^{80,102}$, these drugs could be an ideal option for the treatment of patients with diabetes mellitus at such risk ${ }^{103}$.

During the COVID-19 pandemic, having overweight or obesity has several disadvantages; for example, the presence of chronic low-grade inflammation and a compromised immune system ${ }^{104}$. People with COVID-19 and obesity showed lower lung compliance and worse health outcomes than those with COVID-19 but without obesity, and health-care providers have difficulties in finding the right mask size and problems with mask ventilation $^{104}$. Therefore, GLP1 analogues can be recommended for patients with obesity and T2DM because they have weight-reducing properties ${ }^{105}$. However, initiating or maintaining such therapies in acute or critical situations (such as severe COVID-19) is not recommended because they will take time to become effective, due to slow up-titration, and might provoke nausea and vomiting $^{106}$.

Sodium-glucose cotransporter 2 inhibitors. Sodiumglucose cotransporter 2 (SGLT2) inhibitors (SGLT2is) act on the kidney to reduce blood levels of glucose and are used to treat T2DM. In patients with T2DM, 
treatment with SGLT2is reduced infiltration of inflammatory cells into arterial plaques ${ }^{107}$ and decreased the mRNA expression levels of some cytokines and chemokines, such as TNF, IL-6 and monocyte chemoattractant protein $1(\mathrm{MCP} 1)^{108}$. However, SGLT2i treatment can cause ketoacidosis ${ }^{109}$, especially in critically ill patients. Importantly, SGLT2is have profound effects on urinary glucose and sodium excretion, resulting in osmotic diuresis and potentially dehydration ${ }^{109}$, and increased urinary uric acid excretion, which has been suggested to be a risk factor for acute kidney injury through both urate crystal-dependent and crystal-independent mechanisms ${ }^{110}$. As such, the use of SGLT2is might be difficult in patients under critical care, who need meticulous control of their fluid balance. In addition, these drugs must be discontinued in the face of a reduced estimated glomerular filtration rate, which limits their glucose-lowering effects substantially, and will be a typical risk in critically ill patients. Nonetheless, an international study is ongoing to evaluate the effect of dapagliflozin versus placebo, given once daily for 30 days, in reducing disease progression, complications and all-cause mortality in all patients admitted with COVID-19 (NCT04350593). The result of this study might help reveal the implications of the use of SGLT2is in such patients.

Thiazolidinedione. The thiazolidinediones are agonists of the peroxisome proliferator-activated receptor- $\gamma$ $(\operatorname{PPAR} \gamma)$, a nuclear receptor that regulates the transcription of various genes involved in glucose and lipid metabolism ${ }^{111}$. In many basic and animal studies, thiazolidinediones have been found to reduce insulin resistance and to have putative anti-inflammatory and antioxidant effects, contributing to their antiatherosclerotic properties ${ }^{112,113}$. Given these properties, thiazolidinediones have the potential to mediate protective effects on the cardiovascular system. In a review of RCTs that compared thiazolidinediones with placebo for the secondary prevention of stroke and related vascular events in people who had experienced stroke or transient ischaemic attack, thiazolidinedione treatment reduced the recurrence of stroke compared with placebo ${ }^{114}$. However, thiazolidinedione therapy was associated with weight gain and oedema and more importantly was associated with aggravation of heart failure ${ }^{115}$. These results do not support the use of thiazolidinedione in patients with COVID-19. More clinical trials are needed to optimize the risk-benefit ratio of using thiazolidinediones in patients with COVID-19.

\section{Use of antidiabetic medications}

Based on the data from previous basic and clinical studies and the most recent information available from current publications, we propose some guidelines for the use of glucose-lowering medications in patients with T2DM and COVID-19, according to the clinical status of COVID-19, which is based on the WHO clinical progression scale ${ }^{116}$ (FIG. 4; Supplementary Table 3). Few published recommendations exist for the use of these medications during the COVID-19 pandemic $^{16}$. In patients with COVID-19, we should be prepared for acute hyperglycaemia (that might be exacerbated by inflammation-associated insulin resistance), and we face the need to provide appropriate glycaemic control effectively and rapidly. The choice of agents should be guided mainly by their presumed effectiveness and by potential or actual adverse effects. In line with the review by Drucker $^{16}$, we recommend DPP4is and GLP1 analogues in patients with mild to moderate symptoms because these agents have proven glucose-lowering efficacy in hospital settings, as well as in outpatient clinics. However, insufficient data are available to support the use of these agents instead of insulin in critically ill patients with T2DM and COVID-19, especially if the therapy needs to be initiated under conditions of severe illness (FIG. 4; Supplementary Table 3). The anti-inflammatory actions of DPP4is and GLP1 analogues suggest the need for clinical trials with such agents in patients with T2DM and COVID-19.

In line with Drucker's recommendation ${ }^{16}$, we suggest using mainly insulin for critically ill patients with diabetes mellitus infected with SARS-CoV-2. Optimal glucose control using insulin infusion statistically significantly reduced IL-6 and D-dimer levels and improved severity in patients with COVID-19 with or without diabetes mellitus ${ }^{117}$. Metformin has shown anti-inflammatory actions in preclinical studies, and furthermore metformin treatment reduced the circulating levels of inflammation biomarkers in people with $\mathrm{T}_{2} \mathrm{DM}^{118}$. In a study that compared the outcomes in hospitalized Chinese patients with COVID-19 and diabetes mellitus (mean age 64 years, 53\% men) between 104 patients receiving metformin and 179 patients not receiving metformin, in-hospital mortality was significantly lower in the those receiving metformin $(2.9 \%$ versus $12.3 \% ; P=0.01)^{119}$; however, this finding might have been driven by selection bias, as patients with severe respiratory problems cannot be treated with metformin. Therefore, physicians should be conservative in their prescription of glucose-lowering medications, with the above considerations in mind, because there is little evidence proving superiority in the efficacy and safety of any specific medication in patients with diabetes mellitus and COVID-19.

Specific recommendations for the treatment of ketoacidosis in patients with COVID-19 have been published ${ }^{120}$, with an emphasis on subcutaneous insulin regimens. Frequent blood glucose and ketone body monitoring is mandatory in patients with COVID-19 and hyperglycaemia. Fluid and electrolyte management in patients with COVID-19 and impaired respiratory function should follow general recommendations ${ }^{121,122}$; no specific guidance exists for fluid and electrolyte management in patients with diabetes mellitus and COVID-19.

\section{COVID-19 and T1DM}

So far, information regarding the effect of diabetes mellitus on COVID-19 often has not differentiated between the major types ${ }^{123}$ and is mostly related to T2DM owing to the high prevalence of this form of diabetes mellitus $^{11,19}$. Some important information is available specifically for T1DM, as discussed in this section. 


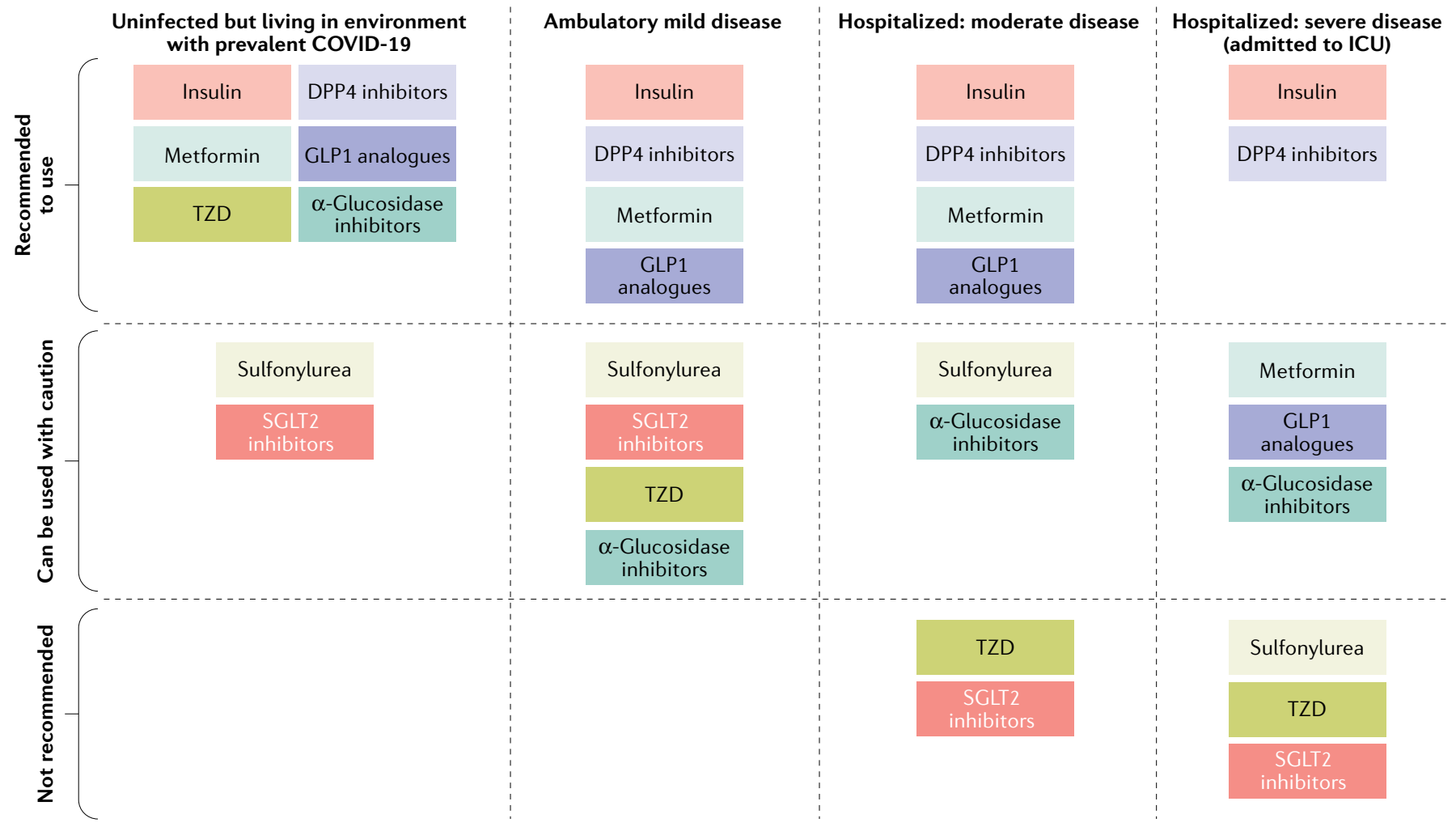

Fig. 4 | Use of antidiabetic medications in patients with T2DM and COVID-19. Coronavirus disease 2019 (COVID-19) severity is based on the WHO clinical progression scale ${ }^{116}$. Insulin is mainly recommended for critically ill patients with diabetes mellitus infected with severe acute respiratory syndrome coronavirus 2 (SARS-CoV-2). Optimal glucose control using insulin infusion statistically significantly reduced inflammatory cytokines and improved severity of COVID-19 (REF. ${ }^{117}$ ). Metformin can be used for uninfected patients with type 2 diabetes mellitus (T2DM) or ambulatory patients with mild COVID-19. However, it should be noted that metformin is not encouraged for use in critically ill patients. Sulfonylurea can be used in uninfected patients with T2DM, but it is not recommended in patients with severe COVID-19 because it can provoke hypoglycaemia. Thiazolidinediones have the potential to mediate protective effects on the cardiovascular system ${ }^{114}$. However, thiazolidinedione therapy induces weight gain and oedema and tends to aggravate heart failure ${ }^{115}$. These results do not support its use in patients with severe COVID-19. Dipeptidyl peptidase 4 (DPP4) inhibitors are one of the most frequently prescribed medications without serious adverse events. DPP4 inhibitor therapy has proved neutral in terms of major adverse cardiac events in previous cardiovascular outcome trials ${ }^{79,80}$. Therefore, DPP4 inhibitors can be recommended for use in most patients with a broad spectrum of severity of COVID-19. Given that beneficial roles of glucagon-like peptide 1 (GLP1) analogues for the prevention of cardiovascular disease (CVD) and kidney disease are well established ${ }^{80,102}$, these drugs could be an ideal option for the treatment of patients with T2DM at risk of CVD and kidney disease ${ }^{103}$. Sodium-glucose cotransporter 2 (SGLT2) inhibitor treatment induces osmotic diuresis and potentially dehydration ${ }^{109}$, which has been suggested to be a risk factor for acute kidney injury and ketoacidosis ${ }^{110}$. As such, the use of SGLT2 inhibitors is not recommended in patients under critical care. ICU, intensive care unit; TZD, thiazolidinedione.
Newly diagnosed T1DM. Case reports have described patients with newly diagnosed T1DM with ketoacidosis occurring at the onset of COVID-19 (REF. ${ }^{124}$ ), and patients with newly diagnosed T1DM without ketoacidosis in whom ketoacidosis occurred several weeks after apparent recovery from COVID-19 (REF. ${ }^{125}$ ). These findings raise the question as to whether SARS-CoV-2 can trigger this metabolic disease. One series found 29 patients who were not known to have diabetes mellitus who developed hyperglycaemia during treatment for COVID-19, some of whom had a normal $\mathrm{HbA}_{1 \mathrm{c}}$ level on admission ${ }^{126}$. However, fewer paediatric patients with T1DM than expected were admitted to specialized Italian diabetes centres ${ }^{127}$. By contrast, specialized hospitals in northwest London, UK, saw more patients presenting with severe ketoacidosis than expected, suggesting a potential increase in numbers of patients with new-onset $\mathrm{T}_{1 \mathrm{DM}}{ }^{128}$. These contradictory findings might be explained by the small patient numbers analysed: they could have been down to chance, or they could be caused by changes in the availability of medical services during the COVID-19 pandemic. A population-based study from Germany found no deviation from the projected numbers of newly diagnosed paediatric patients with $\mathrm{T}_{1 D M}{ }^{129}$. However, the same study found a statistically significant increase in diabetic ketoacidosis and severe ketoacidosis in children and adolescents presenting with new-onset $\mathrm{T}_{1 \mathrm{DM}} \mathrm{D}^{130}$. A probable explanation is that this finding reflects patients trying to delay hospital admission because of their fear of acquiring SARS-CoV-2 infection. As the COVID-19 pandemic progresses and larger numbers of patients are studied, it will become more apparent if a true link exists between COVID-19 and new-onset T1DM.

Metabolic control of outpatients with T1DM. Several groups from Italy, Spain and the UK have reported that patients with T1DM and without COVID-19 have shown no deteriorations in glycaemic control, and often even show improvements in control, during the 
Disseminated intravascular coagulation

A condition that causes abnormal blood clotting throughout the body's small blood vessels pandemic compared with a control period before the pandemic ${ }^{131-133}$. During lockdown, self-reported physical activity was found to be reduced ${ }^{133,134}$ and more consistent patterns of nutrient intake and sleep were found ${ }^{133}$; these findings might reflect conditions under which glycaemic control is easier to achieve. This effect might differ from the situation in developing countries with reduced access to food, medications, blood glucose test strips and medical services ${ }^{135,136}$. The COVID-19 pandemic has also offered opportunities for remote consultation and telemedicine, which might contribute to the glycaemic control patterns seen in developed countries ${ }^{137,138}$.

Hospitalized patients with T1DM and COVID-19. A population-based analysis from Belgium showed a similar risk of hospitalization in people with T1DM than in normoglycaemic individuals $(0.21 \% \text { versus } 0.17 \%)^{139}$. In this study and another from the USA, hospitalized patients with T1DM being treated for COVID-19 had metabolic characteristics similar to patients with T1DM who were hospitalized owing to other diagnoses, and the levels of $\mathrm{HbA}_{1 c}$ were not higher in the patients with COVID-19 (REFS ${ }^{139,140}$ ). However, plasma concentrations of glucose were higher at the time of admission in patients with T1DM and COVID-19 than in patients without non-COVID-19 diagnoses, indicating some acute deterioration in glycaemic control ${ }^{139}$. Worse outcomes in patients with T1DM and COVID-19 (defined as tracheal intubation or death up to day 7 of hospital treatment) seemed to be confined to patients aged $\geq 75$ years $^{141}$.

T1DM and COVID-19 outcomes. Two population-based analyses from the UK clearly indicated a higher mortality in patients with T1DM compared with a population without T1DM ${ }^{11,19}$. Patients with T1DM at particular risk were older, had increased $\mathrm{HbA}_{1 \mathrm{c}}$ levels, arterial hypertension, renal functional impairment and previous cardiovascular events (myocardial infarction, stroke or heart failure $)^{11,19}$. These data support the association between T1DM and poor COVID-19 outcomes.

\section{RAAS inhibitors and statins}

There have been relevant debates regarding benefits or harms related to the use of ACE inhibitors or angiotensin receptor blockers during the COVID-19 pandemic. In addition to classic RAAS, alternative components, including ACE2, angiotensin-(1-7), angiotensin-(1-9) and the Mas receptor, might be involved in the entry and progression of SARS-CoV-2 (FIG. 2). Many international medical societies recommend continuing RAAS inhibitors because there is no proven harm in using them in the context of diabetes mellitus and COVID-19.

The anti-inflammatory and immune-modulatory effects of 3-hydroxy-3-methyl-glutaryl-CoA reductase inhibitors, or statins, suggest that they might be beneficial for treating influenza and bacterial infections ${ }^{142,143}$ A study from China found that statin use was associated with a lower risk of all-cause mortality and a favourable recovery profile in hospitalized patients with COVID-19 $\left(\mathrm{REF}^{144}\right)$. However, the benefit associated with statin therapy needs to be validated in RCTs. More information about the RAAS system, including ACE2 and statins, is presented in the Supplementary Box.

\section{Thromboembolic events}

Evidence suggests that COVID-19 considerably increases the likelihood of thromboembolic events, which represent a predominant cause of death ${ }^{6,145,146}$. The first evidence of abnormal coagulation parameters associated with COVID-19 appeared in early reports from China. For example, the baseline characteristics of the first 99 patients hospitalized in Wuhan found that $6 \%$ had an elevated activated partial thromboplastin time, 5\% showed elevated prothrombin and $36 \%$ had elevated D-dimer ${ }^{6}$. Another study from China found that patients who died from COVID-19 had statistically significantly increased levels of D-dimer and fibrin degradation products ${ }^{60}$. In this study that included middle-aged Chinese patients with COVID-19, more than $71 \%$ of those who died fulfilled the criteria for disseminated intravascular coagulation, but only $0.6 \%$ of the survivors belonged in this category ${ }^{60}$. Of note, 11 studies thus far have found high rates of venous thromboembolism in patients diagnosed with COVID-19 (REF. ${ }^{147}$ ).

COVID-19-associated coagulopathy ranges from mild alterations in laboratory test outcomes to disseminated intravascular coagulation with a predominant phenotype of thrombotic and/or multiple organ failure $^{148}$. The profound inflammatory response to SARS-CoV-2 infection leads to the development of coagulation abnormalities ${ }^{146}$. Vascular endothelial dysfunction seems to contribute to the pathophysiology of microcirculatory changes in patients with SARS-CoV-2 infection $^{149}$. Importantly, SARS-CoV-2 can enter and infect endothelial cells via the ACE2 receptor ${ }^{150}$, with viral replication causing inflammatory cell infiltration, endothelial cell apoptosis and microvascular prothrombotic effects ${ }^{151}$. Post-mortem examinations of patients who died with SARS-CoV-2 infection have demonstrated viral inclusions within endothelial cells and sequestered mononuclear and polymorphonuclear cellular infiltration, with evidence of endothelial apoptosis ${ }^{151}$. Thus, evidence suggests that an increased release of coagulation factors and dysregulation and destruction of the endothelial cells are the main mechanisms of the increase in thromboembolism in patients with COVID-19 $\left(\right.$ REF. $\left.{ }^{148}\right)$. Endothelial dysfunction might also explain reports of cerebrovascular complications in younger patients, and in patients with myocardial ischaemia and/or thromboembolic complications ${ }^{151,152}$.

\section{Thromboembolic risk in patients with diabetes melli-} tus. Several publications have reported an increased thromboembolic risk among patients with diabetes mellitus outside the specific situation of SARS-CoV-2 infection. For example, a population-based study found that patients with T2DM exhibited an increased risk of venous thromboembolism compared with controls (HR 1.44, 95\% CI 1.27-1.63) ${ }^{153}$. Furthermore, the risks of pulmonary embolism were greater in the patients with T2DM than in the controls (HR 1.52, 95\% CI $1.22-1.90)^{153}$. Another study found that the incidence 
of deep vein thrombosis (DVT) after total knee replacement was statistically significantly higher in patients with diabetes mellitus than in those without ${ }^{154}$. Diabetes mellitus was also found to be associated with an increase of more than twofold in the risk of ulcer formation after $\mathrm{DVT}^{155}$. Thus, patients with diabetes mellitus are already in a high-risk category for a thromboembolic event or stroke ${ }^{156,157}$.

To prevent such complications, patients with diabetes mellitus who are at risk of SARS-CoV-2 infection should try not to be sedentary for long periods, as regular physical activity is associated with decreased incidence of thromboembolism ${ }^{158}$. Instead, these individuals should try to engage in physical activity to improve blood circulation. Appropriate simple exercises for performance at home (ankle rotations and calf massage) are available and effective $\mathrm{e}^{159}$ and should be recommended. Patients who experience pain in their legs, shortness of breath or chest pain must not hesitate to contact their physician owing to suspected thromboembolic complications.

Considering an increased thromboembolic risk among patients with diabetes mellitus ${ }^{153-157}$, we propose that physicians should consider prescribing antiplatelet or anticoagulating agents more actively in patients with diabetes mellitus to prevent thromboembolic events and their complications during the COVID-19 pandemic.

The precise molecular and cellular mechanisms behind the higher coagulability of blood among patients with COVID-19 is currently poorly understood and conventional prophylaxis does not seem to be always effective in the prevention of thromboembolism ${ }^{160}$. However, anticoagulant therapy (low molecular weight heparin) produced better prognoses in patients with severe COVID-19 at high thromboembolic risk, such as those with elevated D-dimer levels ${ }^{161}$. Therefore, it might be prudent to start anticoagulant therapy in hospitalized patients with moderate to severe COVID-19, even though it might not be necessary in patients with a mild course of the disease.

Although the evidence supporting any direct effects of GLP1 analogues on the risk of thromboembolism is limited, several animal studies have found that treatment with GLP1 analogues inhibits atheroma formation and stabilizes plaques in carotid arteries and aortic arches $^{100,162}$. Administration of GLP1 in vitro decreased the expression of matrix metalloproteinases 2 and MCP1 and the translocation of NF- $\mathrm{BB}-\mathrm{p} 65$, which are linked to a high risk of thromboembolism ${ }^{100}$. A cardiovascular outcome study found that therapy with dulaglutide, a long-acting GLP1 analogue, decreased the incidence of stroke in patients with T2DM ${ }^{163}$. Taken together, it would be beneficial in patients with diabetes mellitus to choose antidiabetic agents that might be able to decrease the risk of thromboembolic events.

Potential drug interactions. Potential interactions might occur between investigational drugs for COVID-19 and commonly administered oral anticoagulants or antiplatelet agents. A combination agent of lopinavir and ritonavir, two protease inhibitors, is used empirically for treating patients with COVID-19 in some countries, including China and India ${ }^{164,165}$. These protease inhibitors inhibit cytochrome P450 3A4 (CYP3A4) enzyme metabolism, resulting in reduced levels of the active metabolite of the antiplatelet agent clopidogrel. By contrast, these protease inhibitors might increase the antiplatelet effects of ticagrelor by inhibiting its metabolism ${ }^{166}$. The anticoagulant vitamin $\mathrm{K}$ antagonists, such apixaban and betrixaban, require dose adjustment, which could be adversely affected by interactions with protease inhibitors. By contrast, the anticoagulant effects of edoxaban and rivaroxaban, non-vitamin $\mathrm{K}$ antagonist oral anticoagulants, can be increased substantially by lopinavir and ritonavir, discouraging concomitant administration with these drugs ${ }^{167}$. Therefore, care should be taken in prescribing drugs that might affect the activity of CYP3A4 because they might affect the effects of antiplatelet agents or anticoagulants that are metabolized through the CYP3A4 system ${ }^{168}$. Remdesivir is a nucleotide analogue inhibitor of RNA-dependent RNA polymerase and has shown beneficial effects in shortening the time to recovery in adults hospitalized with COVID-19 in a preliminary study ${ }^{169}$. Remdesivir was found to have no significant interactions with antiplatelet agents or anticoagulants ${ }^{166,168}$. In general, no major drug-drug interactions are known to occur between investigational COVID-19 therapies and parenteral anticoagulants.

Taken together, it is reasonable to assess the risk of thromboembolism and to consider pharmacological thromboprophylaxis in patients with diabetes mellitus, especially if they have other thromboembolic risk factors or they are hospitalized with COVID-19 (REF. ${ }^{147}$ ).

\section{COVID-19 treatments and metabolism}

The global pandemic of COVID-19 has accelerated the race to find effective prevention and treatment for SARS-CoV-2 infection ${ }^{170}$. Currently, more than 1,800 clinical trials targeting viral entry and replication and immune responses to infection are ongoing; however, the efficacy of most drugs has not yet been proven (ClinicalTrials. gov database of COVID-19 interventional studies). Candidates for COVID-19 therapy can affect glucose metabolism pharmacologically or through the modulation of inflammation and the immune system (TABLE 2; Supplementary Table 2). Thus, these drugs require particular consideration in patients with diabetes mellitus.

Antiviral therapies. Camostat mesylate is a serine protease inhibitor being investigated for its ability to inhibit viral entry, as it inhibits transmembrane protease serine 2 (TMPRSS2), which facilitates viral entry into the host cell ${ }^{171}$. It was reported that camostat mesylate treatment reduced the incidence of new-onset diabetes mellitus in patients with chronic pancreatitis ${ }^{172}$. This drug improved glycaemia and insulin resistance and decreased lipid accumulation in animal models ${ }^{173,174}$. The antimalaria drugs chloroquine and hydroxychloroquine have been used to treat SARS-CoV-2 infection despite their potential adverse effects ${ }^{175,176}$. The two main mechanisms of action of hydroxychloroquine are believed to be via its restriction of viral spike protein cleavage at the ACE2 binding site, and its anti-inflammatory and immunomodulatory properties ${ }^{177}$. Hydroxychloroquine 
also has glucose-lowering efficacy by increasing insulin sensitivity and improving pancreatic $\beta$-cell function ${ }^{178}$, which has enabled hydroxychloroquine to be prescribed as an antidiabetic medication in some countries ${ }^{179}$. Therefore, adjustment of pre-existing antidiabetic drugs might be needed to avoid hypoglycaemia in uncommon cases of patients with diabetes mellitus who are taking hydroxychloroquine ${ }^{180-182}$. Of note, studies have shown conflicting results in the efficacy of hydroxychloroquine in the treatment of patients with COVID-19 (REFS ${ }^{183,184}$ ). More well-designed studies are urgently needed to evaluate its therapeutic efficacy.

Protease inhibitors such as lopinavir and ritonavir have been reported to increase the risk of hyperglycaemia ${ }^{185,186}$ and new-onset diabetes mellitus ${ }^{187}$, to exacerbate pre-existing diabetes mellitus and occasionally to induce the development of diabetic ketoacidosis ${ }^{188}$. In patients with HIV infection, these drugs reduced insulin sensitivity and $\beta$-cell function by up to $50 \%{ }^{185}$. Another issue with protease inhibitors is pharmacological interactions with co-administered glucose-lowering drugs. For example, ritonavir acts as an inhibitor of CYP3A4/5 $\left(\mathrm{REF}^{189}\right)$, increasing plasma concentrations of the DPP4i saxagliptin, and as an inducer of uridine $5^{\prime}$-diphospho-glucuronosyltransferase $\mathrm{e}^{190}$, decreasing concentrations of the SGLT2i canagliflozin. Therefore, frequent blood glucose monitoring and dosing adjustments are recommended for patients treated with these drug combinations. Remdesivir, a nucleotide analogue inhibitor of RNA-dependent RNA polymerase, improved hyperglycaemia, insulin resistance, fatty liver and endotoxaemia in mice fed a high-fat diet ${ }^{191}$. By contrast, increases in blood levels of glucose were similar between the remdesivir-treated and placebo-treated groups in two RCTs with multiethnic groups ${ }^{169}$ and Chinese patients ${ }^{192}$. Thus, additional evidence is needed to elucidate its effect on glucose metabolism.

Adjunctive therapies. Adjunctive therapies are used to prevent the progression of COVID-19 to more severe forms, such as ARDS and multi-organ failure during the hyperinflammatory phase. However, these drugs can also influence glucose metabolism. For example, IL-6 receptor inhibitors, a possible therapeutic option in patients severely ill with COVID-19 who have extensive lung lesions and high IL-6 levels ${ }^{193}$, had beneficial effects on glucose intolerance and insulin resistance in patients with rheumatoid arthritis ${ }^{194}$. Furthermore, anakinra, an IL- $1 \beta$ inhibitor that significantly improved respiratory function in patients with severe COVID-19 (REF. ${ }^{195}$ ), improved glycaemia and $\beta$-cell function in patients with T2DM ${ }^{196}$. By contrast, canakinumab, another IL- $1 \beta$ inhibitor that is under investigation in a clinical trial for the treatment of COVID-19 (REF. ${ }^{197}$ ), was not effective in the treatment of recent-onset $\mathrm{T}^{1} \mathrm{DM}^{198}$. In animal studies, Janus kinase $1 / 2$ inhibitors and Bruton's tyrosine kinase inhibitors, other investigational agents for COVID-19 treatment ${ }^{199}$, improved glycaemia ${ }^{200,201}$ and insulitis ${ }^{200}$ and impaired the levels of anti-insulin B lymphocytes ${ }^{202}$ and insulin antibodies ${ }^{203}$, which might have protective roles in T1DM. TNF inhibitors, particularly adalimumab, are promising therapeutic options for mitigating the inflammatory stage in COVID-19 (REF. ${ }^{204}$ ). The use of TNF inhibitors improved hyperglycaemia, insulin resistance and $\beta$-cell function in patients with active rheumatoid arthritis ${ }^{205}$.

Systemic corticosteroids are well known to induce hyperglycaemia, primarily by increasing postprandial levels of glucose, insulin resistance and pancreatic $\beta$-cell dysfunction ${ }^{206}$, that often necessitates the initiation of insulin therapy. Contrary to this concern, intravenous dexamethasone therapy statistically significantly increased the number of ventilator-free days among patients with severe ARDS and COVID-19 $\left(\right.$ REFS $\left.^{62,207}\right)$. Furthermore, a meta-analysis of clinical trials showed that systemic corticosteroid therapy is associated with reduced short-term all-cause mortality in patients with severe COVID-19 (REF. ${ }^{208}$ ). Hydrocortisone treatment in different regimens also showed a tendency to produce a better hospital course in these patients ${ }^{209}$. However, another study failed to prove any beneficial effect of low-dose hydrocortisone in the treatment of patients with COVID-19 (REF. $\left.{ }^{210}\right)$. The less than optimal dose might be a reason for these disappointing results. Further investigation is required to elucidate the effects of pharmacological treatments for COVID-19 on glucose metabolism in patients with diabetes mellitus.

\section{Conclusions}

During the COVID-19 pandemic, patients with diabetes mellitus should be aware that COVID-19 can increase blood levels of glucose and, as such, they should follow clinical guidelines for the management of diabetes mellitus more strictly, as described here. We provide the following general guidance for patients and health-care providers: patients should be extra vigilant regarding their adherence to prescribed medications (including insulin injections) and their blood levels of glucose, which should be checked more frequently than previously. If blood concentrations of glucose are consistently higher than usual, patients should consult their physician. In the light of current global quarantine policies, more emphasis needs to be placed by health-care providers on healthy food intake and physical activity in patients with diabetes mellitus. If patients experience symptoms such as a dry cough, excessive sputum production or fever, or show a sudden rise in glucose level, they should be advised to consult their physician immediately. Furthermore, it is strongly recommended that patients should strictly adhere to the recommendations of their doctor and be wary of messages communicated by various types of media (including the internet), which often might not stand scientific scrutiny. Most importantly, general precautions should be strictly followed by both health-care providers and their patients, such as social distancing, wearing a mask, washing hands and using disinfectants, to reduce the risk of infection in patients with diabetes mellitus. Telehealth or remote consultations might help reduce the risk posed by direct physical contact between patients and medical personnel. These could be further ways to minimize the risk of SARS-CoV-2 transmission and at the same time provide continued and safe medical care to the general public. 
Coronavirus infections are proven to have a huge effect on the management of diabetes mellitus because they aggravate inflammation and alter immune system responses, leading to difficulties in glycaemic control. SARS-CoV-2 infection also increases the risk of thromboembolism and is more likely to induce cardiorespiratory failure in patients with diabetes mellitus than in patients without diabetes mellitus. All of these mechanisms are now believed to contribute to the poor prognosis of patients with diabetes mellitus and COVID-19. During the COVID-19 pandemic, tight glycaemic control and management of cardiovascular risk factors are crucial for patients with diabetes mellitus. Medications used for both diabetes mellitus and CVD should be adjusted accordingly for people at high risk of SARS-CoV-2 infection. Two experimental agents (dexamethasone and hydroxychloroquine) have shown some promise as treatment agents ${ }^{62,183,207}$. Based on these results, combined treatment with these two agents might be more beneficial than either agent alone. However, it should be kept in mind that the efficacy of dexamethasone in treating COVID-19 was proven in well-designed RCTs such as the RECOVERY study ${ }^{62}$, whereas no such compelling RCTs have been performed for hydroxychloroquine.

In conclusion, the COVID-19 global pandemic poses considerable health hazards, especially for patients with diabetes mellitus. A definitive treatment or vaccine for COVID-19 has yet to be discovered. Therefore, preventing infection in the first place is still the best solution. Under these circumstances, patients with diabetes mellitus should make a determined effort to maintain a healthy lifestyle and to decrease potential risk factors. The optimal management strategy for such patients, such as the choice of glucose-lowering, antihypertensive and lipid-lowering medications, is an important topic for current and future research.

\section{Published online 13 November 2020}

1. Verity, R. et al. Estimates of the severity of coronavirus disease 2019: a model-based analysis. Lancet Infect. Dis. 20, 669-677 (2020).

2. Perez-Saez, J. et al. Serology-informed estimates of SARS-CoV-2 infection fatality risk in Geneva, Switzerland. Lancet Infect. Dis. https://doi.org/ 10.1016/S1473-3099(20)30584-3 (2020).

3. Salje, H. et al. Estimating the burden of SARS-CoV-2 in France. Science 369, 208-211 (2020).

4. Weinberger, D. M. et al. Estimation of excess deaths associated with the COVID-19 pandemic in the United States, March to May 2020. JAMA Intern. Med. 180 1336-1344 (2020)

5. Faust, J. S. $\&$ Del Rio, C. Assessment of deaths from COVID-19 and from seasonal influenza. JAMA Intern. Med. 180, 1045-1046 (2020)

6. Chen, N. et al. Epidemiological and clinical characteristics of 99 cases of 2019 novel coronavirus pneumonia in Wuhan, China: a descriptive study. Lancet 395, 507-513 (2020).

7. Walls, A. C. et al. Structure, function, and antigenicity of the SARS-CoV-2 spike glycoprotein. Cell 181 281-292.e6 (2020).

8. Zhang, H., Penninger, J. M., Li, Y., Zhong, N. \& Slutsky, A. S. Angiotensin-converting enzyme 2 (ACE2) as a SARS-CoV-2 receptor: molecular mechanisms and potential therapeutic target. Intensive Care Med. $\mathbf{4 6}$ 586-590 (2020)

9. Huang, C. et al. Clinical features of patients infected with 2019 novel coronavirus in Wuhan, China. Lancet 395, 497-506 (2020).

10. Wu, Z. \& McGoogan, J. M. Characteristics of and important lessons from the coronavirus disease 2019 (COVID-19) outbreak in China: summary of a report of 72314 cases from the Chinese Center for Disease Control and Prevention. JAMA 323, 1239-1242 (2020).

11. Holman, N. et al. Risk factors for COVID-19-related mortality in people with type 1 and type 2 diabetes in England: a population-based cohort study. Lancet Diabetes Endocrinol. 8, 823-833 (2020).

This article shows that increased COVID-19-related mortality is associated with glycaemic control and cardiovascular and renal complications of diabetes mellitus.

12. Grasselli, G. et al. Baseline characteristics and outcomes of 1591 patients infected with SARS-CoV-2 admitted to ICUs of the Lombardy region, Italy. JAMA 323, 1574-1581 (2020)

13. Goyal, P. et al. Clinical characteristics of Covid-19 in New York City. N. Engl. J. Med. 382, 2372-2374 (2020).

14. Piva, S. et al. Clinical presentation and initial management critically ill patients with severe acute respiratory syndrome coronavirus 2 (SARS-CoV-2) infection in Brescia, Italy. J. Crit. Care 58, 29-33 (2020).

15. Myers, L. C., Parodi, S. M., Escobar, G. J. \& Liu, V. X Characteristics of hospitalized adults with COVID-19 in an integrated health care system in California. JAMA 323, 2195-2198 (2020).
16. Drucker, D. J. Coronavirus infections and type 2 diabetes-shared pathways with therapeutic implications. Endocr. Rev. 41, 457-470 (2020). This review covers the pathophysiology and treatment of type 2 diabetes mellitus in the context of coronavirus infection

17. Yang, J. et al. Prevalence of comorbidities and its effects in patients infected with SARS-CoV-2: a systematic review and meta-analysis. Int. J. Infect. Dis. 94, 91-95 (2020).

18. Zhu, L. et al. Association of blood glucose control and outcomes in patients with COVID-19 and preexisting type 2 diabetes. Cell Metab. 31, 1068-1077 (2020).

This article provides clinical evidence correlating improved glycaemic control with improved outcomes in patients with COVID-19 and pre-existing T2DM

19. Barron, E. et al. Associations of type 1 and type 2 diabetes with COVID-19-related mortality in England: a whole-population study. Lancet Diabetes Endocrinol. 8, 813-822 (2020).

20. Codo, A. C. et al. Elevated glucose levels favor SARS-CoV-2 infection and monocyte response through a HIF-1 a/glycolysis-dependent axis. Cell Metab. 32, 437-446.e5 (2020).

21. Yang, J. K. et al. Plasma glucose levels and diabetes are independent predictors for mortality and morbidity in patients with SARS. Diabet. Med. 23, 623-628 (2006).

22. Kulcsar, K. A., Coleman, C. M., Beck, S. E. \& Frieman M. B. Comorbid diabetes results in immune dysregulation and enhanced disease severity following MERS-CoV infection. JCI Insight 4, e 131774 (2019).

23. Carey, I. M. et al. Risk of infection in type 1 and type 2 diabetes compared with the general population: matched cohort study. Diabetes Care 41, 513-521 (2018).

24. Wu, C. et al. Risk factors associated with acute respiratory distress syndrome and death in patients with coronavirus disease 2019 pneumonia in Wuhan, China. JAMA Intern. Med. 180, 934-943 (2020).

25. Critchley, J. A. et al. Glycemic control and risk of infections among people with type 1 or type 2 diabetes in a large primary care cohort study. Diabetes Care 41 2127-2135 (2018)

26. Wu, L., Girgis, C. M. \& Cheung, N. W. COVID-19 and diabetes: insulin requirements parallel illness severity in critically unwell patients. Clin. Endocrinol. 93, 390-393 (2020).

27. Gianchandani, R. et al. Managing hyperglycemia in the COVID-19 inflammatory storm. Diabetes 69, 2048-2053 (2020).

28. Pal, R., Banerjee, M., Yadav, U. \& Bhattacharjee, S. Clinical profile and outcomes in COVID-19 patients with diabetic ketoacidosis: a systematic review of literature. Diabetes Metab. Syndr. 14, 1563-1569 (2020)

29. Eketunde, A. O., Mellacheruvu, S. P. \& Oreoluwa, P. A review of postmortem findings in patients with COVID-19. Cureus 12, e9438 (2020).
30. Hadjadj, J. et al. Impaired type I interferon activity and inflammatory responses in severe COVID-19 patients. Science 369, 718-724 (2020).

31. Zhang, Q. et al. Inborn errors of type I IFN immunity in patients with life-threatening COVID-19. Science https://doi.org/10.1126/science.abd4570 (2020).

32. Bastard, P. et al. Auto-antibodies against type I IFNs in patients with life-threatening COVID-19. Science https://doi.org/10.1126/science.abd4585 (2020)

33. Coperchini, F., Chiovato, L., Croce, L., Magri, F. \& Rotondi, M. The cytokine storm in COVID-19: an overview of the involvement of the chemokine/ chemokine-receptor system. Cytokine Growth Factor. Rev. 53, 25-32 (2020)

34. Ragab, D., Salah Eldin, H., Taeimah, M., Khattab, R. \& Salem, R. The COVID-19 cytokine storm; what we know so far. Front. Immunol. 11, 1446 (2020).

35. Zeng, Z. et al. Longitudinal changes of inflammatory parameters and their correlation with disease severity and outcomes in patients with COVID-19 from Wuhan, China. Crit. Care 24, 525 (2020).

36. Libby, P. \& Simon, D. I. Inflammation and thrombosis: the clot thickens. Circulation 103, 1718-1720 (2001).

37. Arunachalam, P. S. et al. Systems biological assessment of immunity to mild versus severe COVID-19 infection in humans. Science 369, 1210-1220 (2020).

38. Zhang, Z., Han, N. \& Shen, Y. S100A12 promotes inflammation and cell apoptosis in sepsis-induced ARDS via activation of NLRP3 inflammasome signaling. Mol. Immunol. 122, 38-48 (2020).

39. Sestan, M. et al. Virus-induced interferon- $\gamma$ causes insulin resistance in skeletal muscle and derails glycemic control in obesity. Immunity 49, 164-177. e6 (2018).

40. Channappanavar, R. \& Perlman, S. Pathogenic human coronavirus infections: causes and consequences of cytokine storm and immunopathology. Semin. Immunopathol. 39, 529-539 (2017).

41. Groop, L. C. et al. Glucose and free fatty acid metabolism in non-insulin-dependent diabetes mellitus. Evidence for multiple sites of insulin resistance. J. Clin. Invest. 84, 205-213 (1989).

42. Jose, R. J. \& Manuel, A. COVID-19 cytokine storm: the interplay between inflammation and coagulation. Lancet Respir. Med. 8, e46-e47 (2020).

43. Zhou, F. et al. Clinical course and risk factors for mortality of adult inpatients with COVID-19 in Wuhan China: a retrospective cohort study. Lancet 395 , 1054-1062 (2020).

44. Cheema, A. K. et al. Integrated datasets of proteomic and metabolomic biomarkers to predict its impacts on comorbidities of type 2 diabetes mellitus. Diabetes Metab. Syndr. Obes. 13, 2409-2431 (2020).

45. Cariou, B. et al. Phenotypic characteristics and prognosis of inpatients with COVID-19 and diabetes: the CORONADO study. Diabetologia 63, 1500-1515 (2020).

46. Mehta, P. et al. COVID-19: consider cytokine storm syndromes and immunosuppression. Lancet 395 , 1033-1034 (2020). 
47. Zhang, Y. et al. Coagulopathy and antiphospholipid antibodies in patients with Covid-19. N. Engl. J. Med. 382, e38 (2020)

48. Lee, B. C. \& Lee, J. Cellular and molecular players in adipose tissue inflammation in the development of obesity-induced insulin resistance. Biochim. Biophys. Acta 1842, 446-462 (2014).

49. Weyer, C., Bogardus, C., Mott, D. M. \& Pratley, R. E. The natural history of insulin secretory dysfunction and insulin resistance in the pathogenesis of type 2 diabetes mellitus. J. Clin. Invest. 104, 787-794 (1999).

50. van Erp, E. A. et al. Natural killer cell activation by respiratory syncytial virus-specific antibodies is decreased in infants with severe respiratory infections and correlates with Fc-glycosylation. Clin. Transl. Immunol. 9, e1112 (2020).

51. Wensveen, F. M. et al. NK cells link obesityinduced adipose stress to inflammation and insulin resistance. Nat. Immunol. 16, 376-385 (2015).

52. Kim, J. H. et al. Relationship between natural killer cell activity and glucose control in patients with type 2 diabetes and prediabetes. J. Diabetes Investig. 10, 1223-1228 (2019)

53. Gheblawi, M. et al. Angiotensin-converting enzyme 2: SARS-CoV-2 receptor and regulator of the reninangiotensin system: celebrating the 20th anniversary of the discovery of ACE2. Circ. Res. 126, 1456-1474 (2020).

54. Hikmet, F. et al. The protein expression profile of ACE2 in human tissues. Mol. Syst. Biol. 16, e9610 (2020).

55. Wang, L., Liang, J. \& Leung, P. S. The ACE2/Ang-(1-7)/ Mas axis regulates the development of pancreatic endocrine cells in mouse embryos. PLOS ONE 10, e0128216 (2015).

56. Lu, C. L., Wang, Y., Yuan, L., Li, Y. \& Li, X. Y. The angiotensin-converting enzyme 2/angiotensin (1-7)/ Mas axis protects the function of pancreatic $\beta$ cells by improving the function of islet microvascular endothelial cells. Int. J. Mol. Med. 34, 1293-1300 (2014).

57. Yang, J. K., Lin, S. S., Ji, X. J. \& Guo, L. M. Binding of SARS coronavirus to its receptor damages islets and causes acute diabetes. Acta Diabetol. 47, 193-199 (2010).

58. Bhatraju, P. K. et al. Covid-19 in critically ill patients in the Seattle region - case series. N. Engl. J. Med. 382, 2012-2022 (2020).

59. Arentz, M. et al. Characteristics and outcomes of 21 critically ill patients with COVID-19 in Washington state. JAMA 323, 1612-1614 (2020).

60. Tang, N., Li, D., Wang, X. \& Sun, Z. Abnormal coagulation parameters are associated with poor prognosis in patients with novel coronavirus pneumonia. J. Thromb. Haemost. 18, 844-847 (2020).

61. Wang, S. et al. Fasting blood glucose at admission is an independent predictor for 28-day mortality in patients with COVID-19 without previous diagnosis of diabetes: a multi-centre retrospective study. Diabetologia 63, 2102-2111 (2020).

62. The RECOVERY Collaborative Group. Dexamethasone in hospitalized patients with Covid-19 - preliminary report. N. Engl. J. Med. https://doi.org/10.1056/ NEJMoa2021436 (2020).

63. Drucker, D. J. The biology of incretin hormones Cell Metab. 3, 153-165 (2006).

64. Lambeir, A. M., Durinx, C., Scharpe, S. \& De Meester, I. Dipeptidyl-peptidase IV from bench to bedside: an update on structural properties, functions, and clinical aspects of the enzyme DPP IV. Crit. Rev. Clin. Lab. Sci. 40, 209-294 (2003).

65. Metzemaekers, M., Van Damme, J., Mortier, A. \& Proost, P. Regulation of chemokine activity - a focus on the role of dipeptidyl peptidase IV/CD26. Front. Immunol. 7, 483 (2016).

66. Willemen, M. J. et al. Use of dipeptidyl peptidase-4 inhibitors and the reporting of infections a disproportionality analysis in the World Health Organization VigiBase. Diabetes Care 34, 369-374 (2011)

67. Gorricho, J. et al. Use of oral antidiabetic agents and risk of community-acquired pneumonia: a nested casecontrol study. Br. J. Clin. Pharmacol. 83, 2034-2044 (2017).

68. Li, Y. et al. The MERS-CoV receptor DPP4 as a candidate binding target of the SARS-CoV-2 spike. iScience 23, 101160 (2020)

69. Kleine-Weber, H. et al. Polymorphisms in dipeptidyl peptidase 4 reduce host cell entry of Middle East respiratory syndrome coronavirus. Emerg. Microbes Infect. 9, 155-168 (2020).

70. Inn, K. S. et al. Reduction of soluble dipeptidyl peptidase 4 levels in plasma of patients infected with Middle East respiratory syndrome coronavirus. Virology 518, 324-327 (2018).

71. Mulvihill, E. E. \& Drucker, D. J. Pharmacology, physiology, and mechanisms of action of dipeptidyl peptidase-4 inhibitors. Endocr. Rev. 35, 992-1019 (2014).

72. Varin, E. M. et al. Circulating levels of soluble dipeptidyl peptidase-4 are dissociated from inflammation and induced by enzymatic DPP4 inhibition. Cell Metab. 29, 320-334.e5 (2019).

73. Raj, V. S. et al. Dipeptidyl peptidase 4 is a functional receptor for the emerging human coronavirus-EMC. Nature 495, 251-254 (2013).

74. Abouelkheir, M. \& El-Metwally, T. H. Dipeptidyl peptidase-4 inhibitors can inhibit angiotensin converting enzyme. Eur. J. Pharmacol. 862, 172638 (2019).

75. Jackson, E. K., Dubinion, J. H. \& Mi, Z. Effects of dipeptidyl peptidase IV inhibition on arterial blood pressure. Clin. Exp. Pharmacol. Physiol. 35, 29-34 (2008).

76. Valencia, I. et al. DPP4 and ACE2 in diabetes and COVID-19: therapeutic targets for cardiovascular complications? Front. Pharmacol. 11, 1161 (2020).

77. Lee, S. A. et al. CD26/DPP4 levels in peripheral blood and T cells in patients with type 2 diabetes mellitus. J. Clin. Endocrinol. Metab. 98, 2553-2561 (2013).

78. Romacho, T. et al. DPP4 deletion in adipose tissue improves hepatic insulin sensitivity in diet-induced obesity. Am. J. Physiol. Endocrinol. Metab. 318, E590-E599 (2020).

79. Lim, S., Oh, T. J., Dawson, J. \& Sattar, N. Diabetes drugs and stroke risk: intensive versus conventional glucose-lowering strategies, and implications of recent cardiovascular outcome trials. Diabetes Obes. Metab. 22, 6-15 (2020)

80. Nauck, M. A ., Meier, J. J., Cavender, M. A Abd El Aziz, M. \& Drucker, D. J. Cardiovascular actions and clinical outcomes with glucagon-like peptide-1 receptor agonists and dipeptidyl peptidase-4 inhibitors. Circulation 136, 849-870 (2017).

81. Zhong, J., Maiseyeu, A., Davis, S. N. \& Rajagopalan, S. DPP4 in cardiometabolic disease: recent insights from the laboratory and clinical trials of DPP4 inhibition. Circ. Res. 116, 1491-1504 (2015)

82. Lu, G. et al. Molecular basis of binding between novel human coronavirus MERS-CoV and its receptor CD26. Nature 500, 227-231 (2013).

83. Gorrell, M. D., Gysbers, V. \& McCaughan, G. W. CD26 a multifunctional integral membrane and secreted protein of activated lymphocytes. Scand. J. Immunol. 54, 249-264 (2001)

84. Raj, V. S. et al. Adenosine deaminase acts as a natura antagonist for dipeptidyl peptidase 4-mediated entry of the Middle East respiratory syndrome coronavirus. J. Virol. 88, 1834-1838 (2014).

85. Baggio, L. L. et al. Plasma levels of DPP4 activity and SDPP4 are dissociated from inflammation in mice and humans. Nat. Commun. 11, 3766 (2020).

86. Kitagawa, N. et al. Dipeptidyl peptidase-4 inhibitors have adverse effects for the proliferation of human T cells. J. Clin. Biochem. Nutr. 63, 106-112 (2018).

87. Dalan, R. et al. The association of hypertension and diabetes pharmacotherapy with COVID-19 severity and immune signatures: an observational study. Eur. Heart J. Cardiovasc. Pharmacother. https:/ doi.org/10.1093/ehjcvp/pvaa098 (2020).

88. lacobellis, G COVID-19 and diabetes: can DPP4 inhibition play a role? Diabetes Res. Clin. Pract. 162, 108125 (2020).

89. Solerte, S. et al. Sitagliptin treatment at the time of hospitalization was associated with reduced mortality in patients with type 2 diabetes and COVID-19. a multicenter case-control retrospective observational study. Diabetes Care https://doi.org/10.2337/ dc20-1521 (2020).

90. Mirani, M. et al. Impact of comorbidities, glycemia at admission, and DPP-4 inhibitors in type 2 diabetic patients with COVID-19: a case series from an academic hospital in Lombardy, Italy. Diabetes Care https://doi.org/10.2337/dc20-1340 (2020).

91. Lim, S., Kim, K. M. \& Nauck, M. A. Glucagon-like peptide-1 receptor agonists and cardiovascular events: class effects versus individual patterns. Trends Endocrinol. Metab. 29, 238-248 (2018).

92. Yusta, B. et al. GLP-1R agonists modulate enteric immune responses through the intestinal intraepithelial lymphocyte GLP-1R. Diabetes 64, 2537-2549 (2015)

93. Hogan, A. E. et al. Glucagon-like peptide 1 analogue therapy directly modulates innate immune-mediated inflammation in individuals with type 2 diabetes mellitus. Diabetologia 57, 781-784 (2014).

94. Liu, H., Dear, A. E., Knudsen, L. B. \& Simpson, R. W. A long-acting glucagon-like peptide- 1 analogue attenuates induction of plasminogen activator inhibitor type- 1 and vascular adhesion molecules. J. Endocrinol. 201, 59-66 (2009).

95. Arakawa, M. et al. Inhibition of monocyte adhesion to endothelial cells and attenuation of atherosclerotic lesion by a glucagon-like peptide-1 receptor agonist, exendin-4. Diabetes 59, 1030-1037 (2010).

96. Kodera, R. et al. Glucagon-like peptide-1 receptor agonist ameliorates renal injury through its antiinflammatory action without lowering blood glucose level in a rat model of type 1 diabetes. Diabetologia 54, 965-978 (2011)

97. Lee, Y. S. \& Jun, H. S. Anti-inflammatory effects of GLP-1-based therapies beyond glucose control. Mediators Inflamm. 2016, 3094642 (2016).

98. Noyan-Ashraf, M. H. et al. A glucagon-like peptide-1 analog reverses the molecular pathology and cardiac dysfunction of a mouse model of obesity. Circulation 127, 74-85 (2013).

99. Ceriello, A. et al. Glucagon-like peptide 1 reduces endothelial dysfunction, inflammation, and oxidative stress induced by both hyperglycemia and hypoglycemia in type 1 diabetes. Diabetes Care 36 2346-2350 (2013)

100. Lim, S. et al. Attenuation of carotid neointimal formation after direct delivery of a recombinant adenovirus expressing glucagon-like peptide- 1 in diabetic rats. Cardiovasc. Res. 113, 183-194 (2017).

101. Athauda, D. et al. Exenatide once weekly versus placebo in Parkinson's disease: a randomised, double-blind, placebo-controlled trial. Lancet 390 , 1664-1675 (2017).

102. Prattichizzo, F. et al. Glucose-lowering therapies in patients with type 2 diabetes and cardiovascular diseases. Eur. J. Prev. Cardiol. 26, 73-80 (2019).

103. Ceriello, A., Stoian, A. P. \& Rizzo, M. COVID-19 and diabetes management: what should be considered? Diabetes Res. Clin. Pract. 163, 108151 (2020).

104. Lim, S., Shin, S. M., Nam, G. E., Jung, C. H. \& Koo, B. K Proper management of people with obesity during the COVID-19 pandemic. J. Obes. Metab. Syndr. 29, 84-98 (2020)

105. Stoian, A. P., Papanas, N., Prazny, M., Rizvi, A. A. \& Rizzo, M. Incretin-based therapies role in COVID-19 era: evolving insights. J Cardiovasc Pharmacol Ther https://doi.org/10.1177/1074248420937868 (2020).

106. Nauck, M. A. \& Meier, J. J. Management of endocrine disease: are all GLP-1 agonists equal in the treatment of type 2 diabetes? Eur. J. Endocrinol. 181, R211-R234 (2019).

107. Han, J. H. et al. The beneficial effects of empagliflozin an SGLT2 inhibitor, on atherosclerosis in $\mathrm{ApoE}(-/-)$ mice fed a western diet. Diabetologia 60, 364-376 (2017).

108. Garvey, W. T. et al. Effects of canagliflozin versus glimepiride on adipokines and inflammatory biomarkers in type 2 diabetes. Metabolism 85 , 32-37 (2018)

109. Hahn, K. Ejaz, A. A. Kanbay, M. Lanaspa, M. A $\S$ Johnson, R. J. Acute kidney injury from SGLT2 inhibitors: potential mechanisms. Nat. Rev. Nephrol. 12, 711-712 (2016)

110. Hahn, K., Kanbay, M., Lanaspa, M. A., Johnson, R. J. \& Ejaz, A. A. Serum uric acid and acute kidney injury: a mini review. J. Adv. Res. 8, 529-536 (2017).

111. Yki-Jarvinen, H. Thiazolidinediones. N. Engl. J. Med 351, 1106-1118 (2004).

112. Li, A. C. et al. Peroxisome proliferator-activated receptor $\gamma$ ligands inhibit development of atherosclerosis in LDL receptor-deficient mice. J. Clin. Invest. 106, 523-531 (2000).

113. Lim, S. et al. Effect of a new PPAR-gamma agonist, lobeglitazone, on neointimal formation after balloon injury in rats and the development of atherosclerosis. Atherosclerosis 243, 107-119 (2015).

114. Liu, J. \& Wang, L. N. Peroxisome proliferator-activated receptor gamma agonists for preventing recurrent stroke and other vascular events in people with stroke or transient ischaemic attack. Cochrane Database Syst. Rev. 12, CD010693 (2017).

115. Kernan, W. N. et al. Pioglitazone after ischemic stroke or transient ischemic attack. N. Engl. J. Med. 374 , 1321-1331 (2016). 
116. WHO Working Group on the Clinical Characterisation and Management of COVID-19 infection. A minimal common outcome measure set for COVID-19 clinical research. Lancet Infect. Dis. 20, e192-e197 (2020)

117. Sardu, C. et al. Outcomes in patients with hyperglycemia affected by COVID-19: can we do more on glycemic control? Diabetes Care 43, 1408-1415 (2020).

118. Cameron, A. R. et al. Anti-inflammatory effects of metformin irrespective of diabetes status. Circ. Res. 119, 652-665 (2016).

119. Luo, P. et al. Metformin treatment was associated with decreased mortality in COVID-19 patients with diabetes in a retrospective analysis. Am. J. Trop. Med. Hyg. 103, 69-72 (2020).

120. Palermo, N. E., Sadhu, A. R. \& McDonnell, M. E. Diabetic ketoacidosis in COVID-19: unique concerns and considerations. J. Clin. Endocrinol. Metab. 105, 2819-2829 (2020)

121. Hasanin, A. \& Mostafa, M. Evaluation of fluid responsiveness during COVID-19 pandemic: what are the remaining choices? J. Anesth 34, 758-764 (2020).

122. Khan, A. A., Ata, F., Munir, W. \& Yousaf, Z. Fluid replacement versus fluid restriction in COVID-19 associated hyponatremia. Cureus 12, e9059 (2020).

123. Tenforde, M. W. et al. Characteristics of adult outpatients and inpatients with COVID-19-11 academic medical centers, United States, March-May 2020. MMWR Morb. Mortal. Wkly. Rep. 69 841-846 (2020)

124. Potier, L. et al. COVID-19 symptoms masking inaugural ketoacidosis of type 1 diabetes. Diabetes Metab. https://doi.org/10.1016/j.diabet.2020.05.004 (2020).

125. Marchand, L., Pecquet, M. \& Luyton, C. Type 1 diabetes onset triggered by COVID-19. Acta Diabetol. 57, 1265-1266 (2020)

126. Smith, S. M. et al. Impaired glucose metabolism in patients with diabetes, prediabetes, and obesity is associated with severe COVID-19. J. Med. Virol. https://doi.org/10.1002/jmv.26227 (2020)

127. Rabbone, I. et al. Has COVID-19 delayed the diagnosis and worsened the presentation of type 1 diabetes in children? Diabetes Care 43, 2870-2872 (2020).

128. Unsworth, R. et al. New-onset type 1 diabetes in children during COVID-19: multicenter regional findings in the U.K. Diabetes Care 43, e 170-e171 (2020).

129. Tittel, S. R. et al. Did the COVID-19 lockdown affect the incidence of pediatric type 1 diabetes in Germany? Diabetes Care 43, e172-e173 (2020).

130. Kamrath, C. et al. Ketoacidosis in children and adolescents with newly diagnosed type 1 diabetes during the COVID-19 pandemic in Germany. JAMA 324, 801-804 (2020).

131. Mesa, A. et al. The impact of strict COVID-19 lockdown in Spain on glycemic profiles in patients with type 1 diabetes prone to hypoglycemia using standalone continuous glucose monitoring. Diabetes Res. Clin. Pract. 167, 108354 (2020)

132. Dover, A. R. et al. Assessment of the effect of the COVID-19 lockdown on glycaemic control in people with type 1 diabetes using flash glucose monitoring. Diabet. Med. https://doi.org/10.1111/dme. 14374 (2020).

133. Capaldo, B. et al. Blood glucose control during lockdown for COVID-19: CGM metrics in Italian adults with type 1 diabetes. Diabetes Care 43, e88-e89 (2020).

134. Assaloni, R. et al. Coronavirus disease (Covid-19): how does the exercise practice in active people with type 1 diabetes change? A preliminary survey. Diabetes Res. Clin. Pract. 166, 108297 (2020).

135. Klatman, E. L., Besancon, S., Bahendeka, S., Mayige, M. \& Ogle, G. D. COVID-19 and type 1 diabetes: challenges and actions. Diabetes Res. Clin. Pract. 166, 108275 (2020).

136. Verma, A., Rajput, R., Verma, S., Balania, V. K. B. \& Jangra, B. Impact of lockdown in COVID 19 on glycemic control in patients with type 1 diabetes mellitus. Diabetes Metab. Syndr. 14, 1213-1216 (2020).

137. Garg, S. K., Rodbard, D., Hirsch, I. B. \& Forlenza, G. P. Managing new-onset type 1 diabetes during the COVID-19 pandemic: challenges and opportunities. Diabetes Technol. Ther. 22, 431-439 (2020).

138. Venkatesh, N. et al. COVID-19, type 1 diabetes clinical practice, research, and remote medical care: a view from the land down-under. J. Diabetes Sci. Technol. 14, 803-804 (2020)

139. Vangoitsenhoven, R. et al. No evidence of increased hospitalization rate for COVID-19 in community- dwelling patients with type 1 diabetes. Diabetes Care 43, e118-e119 (2020).

140. Vamvini, M., Lioutas, V. A. \& Middelbeek, R. J. W. Characteristics and diabetes control in adults with type 1 diabetes admitted with COVID-19 infection. Diabetes Care 43, e120-e122 (2020).

141. Wargny, M. et al. Type 1 diabetes in people hospitalized for COVID-19: new insights from the CORONADO study. Diabetes Care 43, e174-e177 (2020).

142. Novack, V. et al. The effects of statin therapy on inflammatory cytokines in patients with bacterial infections: a randomized double-blind placebo controlled clinical trial. Intensive Care Med. 35 1255-1260 (2009).

143. Papazian, L. et al. Effect of statin therapy on mortality in patients with ventilator-associated pneumonia: a randomized clinical trial. JAMA 310, 1692-1700 (2013).

144. Zhang, X. J. et al. In-hospital use of statins is associated with a reduced risk of mortality among individuals with COVID-19. Cell Metab. 32 176-187.e4 (2020).

145. Klok, F. A. et al. Confirmation of the high cumulative incidence of thrombotic complications in critically ill ICU patients with COVID-19: an updated analysis. Thromb. Res. 191, 148-150 (2020).

146. Connors, J. M. \& Levy, J. H. COVID-19 and its implications for thrombosis and anticoagulation. Blood 135, 2033-2040 (2020)

147. Moores, L. K. et al. Prevention, diagnosis, and treatment of VTE in patients with coronavirus disease 2019: CHEST guideline and expert panel report. Chest 158, 1143-1163 (2020).

148. Fei, Y., Tang, N., Liu, H. \& Cao, W. Coagulation dysfunction: a hallmark in COVID-19. Arch. Pathol. Lab. Med. 144, 1223-1229 (2020).

149. Oxford, A. E., Halla, F., Robertson, E. B. \& Morrison, B. E. Endothelial cell contributions to COVID-19. Pathogens 9, 785 (2020)

150. Ferrario, C. M. et al. Effect of angiotensin-converting enzyme inhibition and angiotensin II receptor blockers on cardiac angiotensin-converting enzyme 2 . Circulation 111, 2605-2610 (2005).

151. Varga, Z. et al. Endothelial cell infection and endotheliitis in COVID-19. Lancet 395, 1417-1418 (2020).

152. Iba, T. et al. Differential diagnoses for sepsisinduced disseminated intravascular coagulation: communication from the SSC of the ISTH. J. Thromb. Haemost. 17, 415-419 (2019).

153. Chung, W. S., Lin, C. L. \& Kao, C. H. Diabetes increases the risk of deep-vein thrombosis and pulmonary embolism. A population-based cohort study. Thromb. Haemost. 114, 812-818 (2015).

154. Zhao, Z. et al. Diabetes mellitus increases the incidence of deep vein thrombosis after total knee arthroplasty. Arch. Orthop. Trauma. Surg. 134 79-83 (2014)

155. Galanaud, J. P. et al. Predictors of post-thrombotic ulcer after acute DVT: the RIETE registry. Thromb. Haemost. 118, 320-328 (2018).

156. Olesen, K. K. W. et al. Diabetes mellitus is associated with increased risk of ischemic stroke in patients with and without coronary artery disease. Stroke 50 3347-3354 (2019).

157. Overvad, T. F. et al. Duration of diabetes mellitus and risk of thromboembolism and bleeding in atrial fibrillation: nationwide cohort study. Stroke 46, 2168-2174 (2015)

158. Kunutsor, S. K. et al. Physical activity and risk of venous thromboembolism: systematic review and meta-analysis of prospective cohort studies. Eur. J. Epidemiol. 35, 431-442 (2020)

159. Guo, M. et al. Comprehensive functional exercises with patient education for the prevention of venous thrombosis after major gynecologic surgery: a randomized controlled study. Thromb. Res. 178 69-74 (2019).

160. Arepally, G. M. \& Ortel, T. L. Changing practice of anticoagulation: will target-specific anticoagulants replace warfarin? Annu. Rev. Med. 66, 241-253 (2015).

161. Tang, N. et al. Anticoagulant treatment is associated with decreased mortality in severe coronavirus disease 2019 patients with coagulopathy. J. Thromb. Haemost. 18, 1094-1099 (2020).

162. Vinue, A. et al. The GLP-1 analogue lixisenatide decreases atherosclerosis in insulin-resistant mice by modulating macrophage phenotype. Diabetologia 60 , 1801-1812 (2017)

163. Gerstein, H. C. et al. Dulaglutide and cardiovascular outcomes in type 2 diabetes (REWIND): a double-blind, randomised placebo-controlled trial. Lancet 394, 121-130 (2019).

164. Cao, B. et al. A trial of lopinavir-ritonavir in adults hospitalized with severe Covid-19. N. Engl. J. Med. 382, 1787-1799 (2020)

165. Bhatnagar, T. et al. Lopinavir/ritonavir combination therapy amongst symptomatic coronavirus disease 2019 patients in India: protocol for restricted public health emergency use. Indian J. Med. Res. 151 184-189 (2020).

166. Driggin, E. et al. Cardiovascular considerations for patients, health care workers, and health systems during the COVID-19 pandemic. J. Am. Coll. Cardiol. 75, 2352-2371 (2020)

This article describes cardiovascular considerations related to COVID-19 and highlights gaps in knowledge that require further study pertinent to patients, health-care workers and health systems.

167. Mueck, W., Kubitza, D. \& Becka, M. Co-administration of rivaroxaban with drugs that share its elimination pathways: pharmacokinetic effects in healthy subjects. Br. J. Clin. Pharmacol. 76, 455-466 (2013).

168. Sanders, J. M., Monogue, M. L., Jodlowski, T. Z. $\&$ Cutrell, J. B. Pharmacologic treatments for coronavirus disease 2019 (COVID-19): a review. JAMA 323, 1824-1836 (2020).

169. Beigel, J. H. et al. Remdesivir for the treatment of Covid-19 - preliminary report. N. Engl. J. Med. 383, 992-994 (2020)

170. Kupferschmidt, K. \& Cohen, J. Race to find COVID-19 treatments accelerates. Science 367, 1412-1413 (2020).

171. Hoffmann, M. et al. SARS-CoV-2 cell entry depends on ACE2 and TMPRSS2 and is blocked by a clinically proven protease inhibitor. Cell 181, 271-280.e8 (2020).

172. Ito, T. et al. Pancreatic diabetes in a follow-up survey of chronic pancreatitis in Japan. J. Gastroenterol. 42, 291-297 (2007)

173. Jia, D., Taguchi, M. \& Otsuki, M. Synthetic protease inhibitor camostat prevents and reverses dyslipidemia, insulin secretory defects, and histological abnormalities of the pancreas in genetically obese and diabetic rats. Metabolism 54, 619-627 (2005).

174. Albarazanji, K. et al. Intestinal serine protease inhibition increases FGF21 and improves metabolism in obese mice. Am. J. Physiol. Gastrointest. Liver Physiol. 316, G653-G667 (2019).

175. Mercuro, N. J. et al. Risk of QT interval prolongation associated with use of hydroxychloroquine with or without concomitant azithromycin among hospitalized patients testing positive for coronavirus disease 2019 (COVID-19). JAMA Cardiol. 5, 1036-1041 (2020).

176. Bessiere, F. et al. Assessment of QT intervals in a case series of patients with coronavirus disease 2019 (COVID-19) infection treated with hydroxychloroquine alone or in combination with azithromycin in an intensive care unit. JAMA Cardiol. 5, 1067-1069 (2020).

177. Satarker, S. et al. Hydroxychloroquine in COVID-19 potential mechanism of action against SARS-CoV-2. Curr. Pharmacol. Rep. 6, 203-211 (2020).

178. Wasko, M. C. et al. Antidiabetogenic effects of hydroxychloroquine on insulin sensitivity and beta cell function: a randomised trial. Diabetologia $\mathbf{5 8}$ 2336-2343 (2015).

179. Chakravarti, H. N. \& Nag, A. Efficacy and safety of hydroxychloroquine as add-on therapy in uncontrolled type 2 diabetes patients who were using two oral antidiabetic drugs. J. Endocrinol. Invest. https://doi.org/10.1007/s40618-020-01330-5 (2020).

180. Gupta, A. Real-world clinical effectiveness and tolerability of hydroxychloroquine $400 \mathrm{mg}$ in uncontrolled type 2 diabetes subjects who are not willing to initiate insulin therapy (HYQ-Real-World study). Curr. Diabetes Rev. 15, 510-519 (2019).

181. Shojania, K., Koehler, B. E. \& Elliott, T. Hypoglycemia induced by hydroxychloroquine in a type II diabetic treated for polyarthritis. J. Rheumatol. 26, 195-196 (1999).

182. Stoian, A. P., Catrinoiu, D., Rizzo, M \& Ceriello, A Hydroxychloroquine, COVID-19 and diabetes. Why it is a different story. Diabetes Metab. Res. Rev. https:// doi.org/10.1002/dmrr.3379 (2020).

183. COVID-19 RISK and Treatments (CORIST) Collaboration. Use of hydroxychloroquine in hospitalised COVID-19 patients is associated with reduced mortality: Findings from the observational multicentre Italian CORIST study. Eur. J. Intern. Med. https://doi.org/10.1016/j.ejim.2020.08.019 (2020). 
184. Hernandez, A. V., Roman, Y. M., Pasupuleti, V., Barboza, J. J. \& White, C. M. Hydroxychloroquine or chloroquine for treatment or prophylaxis of COVID-19: a living systematic review. Ann. Intern. Med. 173 287-296 (2020)

185. Woerle, H. J. et al. Mechanisms for the deterioration in glucose tolerance associated with HIV protease inhibitor regimens. Diabetes 52, 918-925 (2003).

186. Tsiodras, S., Mantzoros, C., Hammer, S. \& Samore, M. Effects of protease inhibitors on hyperglycemia, hyperlipidemia, and lipodystrophy: a 5-year cohort study. Arch. Intern. Med. 160, 2050-2056 (2000).

187. Brown, T. T. et al. Antiretroviral therapy and the prevalence and incidence of diabetes mellitus in the multicenter AIDS cohort study. Arch. Intern. Med. 165, 1179-1184 (2005).

188. Kan, V. L. \& Nylen, E. S. Diabetic ketoacidosis in an HIV patient: a new mechanism of HIV protease inhibitor-induced glucose intolerance. AIDS 13 , 1987-1989 (1999).

189. Sevrioukova, I. F. \& Poulos, T. L. Structure and mechanism of the complex between cytochrome P4503A4 and ritonavir. Proc. Natl Acad. Sci. USA 107, 18422-18427 (2010)

190. Algeelani, S., Alam, N., Hossain, M. A., Mikus, G. \& Greenblatt, D. J. In vitro inhibition of human UGT isoforms by ritonavir and cobicistat. Xenobiotica 48 764-769 (2018)

191. Li, Y. N. \& Su, Y. Remdesivir attenuates high fat diet (HFD)-induced NAFLD by regulating hepatocyte dyslipidemia and inflammation via the suppression of STING. Biochem. Biophys. Res. Commun. 526, 381-388 (2020)

192. Wang, Y. et al. Remdesivir in adults with severe COVID-19: a randomised, double-blind, placebocontrolled, multicentre trial. Lancet 395, 1569-1578 (2020).

193. Xu, X. et al. Effective treatment of severe COVID-19 patients with tocilizumab. Proc. Natl Acad. Sci. USA 117, 10970-10975 (2020)

194. Castaneda, S et al. Rapid beneficial effect of the IL-6 receptor blockade on insulin resistance and insulin sensitivity in non-diabetic patients with rheumatoid arthritis. Clin. Exp. Rheumatol. 37 , 465-473 (2019)

195. Dimopoulos, G. et al. Favorable anakinra responses in severe Covid-19 patients with secondary hemophagocytic lymphohistiocytosis. Cell Host Microbe 28, 117-123.e1 (2020).

196. Larsen, C. M. et al. Interleukin-1-receptor antagonist in type 2 diabetes mellitus. N. Engl. J. Med. 356 1517-1526 (2007)

197. Sheng, C. C. et al. Canakinumab to reduce deterioration of cardiac and respiratory function in SARS-CoV-2 associated myocardial injury with heightened inflammation (canakinumab in Covid-19 cardiac injury: the three C study). Clin. Cardiol. 43, 1055-1063 (2020).

198. Moran, A. et al. Interleukin-1 antagonism in type 1 diabetes of recent onset: two multicentre, randomised, double-blind, placebo-controlled trials. Lancet 381. 1905-1915 (2013).

199. Bronte, V. et al. Baricitinib restrains the immune dysregulation in severe COVID-19 patients. J. Clin. Invest. https://doi.org/10.1172/JCI141772 (2020).

200. Trivedi, P. M. et al. Repurposed JAK1/JAK2 inhibitor reverses established autoimmune insulitis in NOD mice. Diabetes 66, 1650-1660 (2017)

201. Yang, X., Cao, Z., Wu, P. \& Li, Z. Effect and mechanism of the bruton tyrosine kinase (Btk) inhibitor ibrutinib on rat model of diabetic foot ulcers. Med. Sci. Monit. 25, 7951-7957 (2019)

202. Bonami, R. H. et al. Bruton's tyrosine kinase promotes persistence of mature anti-insulin B cells. J. Immunol. 192, 1459-1470 (2014)

203. Skrabs, C., Pickl, W. F., Perkmann, T., Jager, U. $\&$ Gessl, A. Rapid decline in insulin antibodies and glutamic acid decarboxylase autoantibodies with ibrutinib therapy of chronic lymphocytic leukaemia. J. Clin. Pharm. Ther. 43, 145-149 (2018).

204. Feldmann, M. et al. Trials of anti-tumour necrosis factor therapy for COVID-19 are urgently needed. Lancet 395, 1407-1409 (2020)

205. Stagakis, I. et al. Anti-tumor necrosis factor therapy improves insulin resistance, beta cell function and insulin signaling in active rheumatoid arthritis patients with high insulin resistance. Arthritis Res. Ther. 14, R141 (2012)

206. Bonaventura, A. \& Montecucco, F. Steroid-induced hyperglycemia: an underdiagnosed problem or clinical inertia? A narrative review. Diabetes Res. Clin. Pract. 139, 203-220 (2018).

207. Tomazini, B. M. et al. Effect of dexamethasone on days alive and ventilator-free in patients with moderate or severe acute respiratory distress syndrome and COVID-19: the CoDEX randomized clinical trial. JAMA 324, 1307-1316 (2020).

208. WHO Rapid Evidence Appraisal for COVID-19 Therapies (REACT) Working Group. Association between administration of systemic corticosteroids and mortality among critically ill patients with COVID-19 a meta-analysis. JAMA 324, 1330-1341 (2020).

209. The Writing Committee for the REMAP-CAP Investigators. Effect of hydrocortisone on mortality and organ support in patients with severe COVID-19: the REMAP-CAP COVID-19 corticosteroid domain randomized clinical trial. JAMA 324, 1317-1329 (2020).

210. Dequin, P. F. et al. Effect of hydrocortisone on 21-day mortality or respiratory support among critically ill patients with COVID-19: a randomized clinical trial. JAMA 324, 1298-1306 (2020).

211. Shi, Q. et al. Clinical characteristics and risk factors for mortality of COVID-19 patients with diabetes in Wuhan, China: a two-center, retrospective study. Diabetes Care 43, 1382-1391 (2020)

212. Seiglie, J. et al. Diabetes as a risk factor for poor early outcomes in patients hospitalized with COVID-19. Diabetes Care https://doi.org/10.2337/dc20-1506 (2020).

213. Agarwal, S., Schechter, C., Southern, W., Crandall, J. P. $\&$ Tomer, Y. Preadmission diabetes-specific risk factors for mortality in hospitalized patients with diabetes and coronavirus disease 2019. Diabetes Care 43 2339-2344 (2020).

214. Cheng, X. et al. Metformin is associated with higher incidence of acidosis, but not mortality, in individuals with COVID-19 and pre-existing type 2 diabetes. Cell Metab. 32, 537-547 (2020)

215. Green, G. M., Guan, D., Schwartz, J. G. \& Phillips, W. T. Accelerated gastric emptying of glucose in Zucker type 2 diabetic rats: role in postprandial hyperglycaemia. Diabetologia 40, 136-142 (1997).

216. Muller, M. K. et al. Effects of camostat, a synthetic protease inhibitor, on endocrine and exocrine pancreas of the rat. J. Nutr. 118, 645-650 (1988).

217. von Schonfeld, J., Runzi, M., Goebell, H. \& Muller, M. K. Endocrine and exocrine pancreatic function after camostate-induced growth of the organ. Experientia 51 556-560 (1995)

218. Gerstein, H. C., Thorpe, K. E., Taylor, D. W. $\&$ Haynes, R. B. The effectiveness of hydroxychloroquine in patients with type 2 diabetes mellitus who are refractory to sulfonylureas-a randomized trial. Diabetes Res. Clin. Pract. 55, 209-219 (2002).

219. Wasko, M. C. et al. Hydroxychloroquine and risk of diabetes in patients with rheumatoid arthritis. JAMA 298, 187-193 (2007)

220. McGill, J. B. et al. Low dose chloroquine decreases insulin resistance in human metabolic syndrome bu does not reduce carotid intima-media thickness. Diabetol. Metab. Syndr. 11, 61 (2019).

221. Romanek, R. et al. Chloroquine inhibits glucosetransporter recruitment induced by insulin in rat adipocytes independently of its action on endomembrane $\mathrm{pH}$. Biochem. J. 296, 321-327 (1993).

222. Zhou O et al. Chloroquine increases glucose uptake via enhancing GLUT4 translocation and fusion with the plasma membrane in L6 cells. Cell Physiol. Biochem. 38, 2030-2040 (2016)

223. Noor, M. A., Flint, O. P., Maa, J. F. \& Parker, R. A. Effects of atazanavir/ritonavir and lopinavir/ritonavir on glucose uptake and insulin sensitivity: demonstrable differences in vitro and clinically. AIDS 20, 1813-1821 (2006)

224. Lee, G. A. et al. Effects of ritonavir and amprenavir on insulin sensitivity in healthy volunteers. AIDS 21 2183-2190 (2007)

225. Lee, G. A. et al. Single-dose lopinavir-ritonavir acutely inhibits insulin-mediated glucose disposal in healthy volunteers. Clin. Infect. Dis. 43, 658-660 (2006).

226. Vyas, A. K., Koster, J. C., Tzekov, A. \& Hruz, P. W. Effects of the HIV protease inhibitor ritonavir on GLUT4 knock-out mice. J. Biol. Chem. 285, 36395-36400 (2010).

227. Hruz, P. W., Yan, Q., Struthers, H. \& Jay, P. Y. HIV protease inhibitors that block GLUT4 precipitate acute, decompensated heart failure in a mouse model of dilated cardiomyopathy. FASEB J. 22, 2161-2167 (2008).

228. Hresko, R. C. \& Hruz, P. W. HIV protease inhibitors act as competitive inhibitors of the cytoplasmic glucose binding site of GLUTs with differing affinities for GLUT1 and GLUT4. PLOS ONE 6, e25237 (2011).

229. Bresciani, E. et al. miRNA-218 targets lipin-1 and glucose transporter type 4 genes in 3T3-L1 cells treated with lopinavir/ritonavir. Front. Pharmacol. 10, 461 (2019).

230. Otsuka, Y. et al. Effects of tumor necrosis factor inhibitors and tocilizumab on the glycosylated hemoglobin levels in patients with rheumatoid arthritis; an observational study. PLOS ONE 13 , e0196368 (2018).

231. Sahraoui, A. et al. Anakinra and tocilizumab enhance survival and function of human islets during culture: implications for clinical islet transplantation. Cell Transpl. 23, 1199-1211 (2014).

232. Ruscitti, P. et al. Anti-interleukin-1 treatment in patients with rheumatoid arthritis and type 2 diabetes (TRACK): a multicentre, open-label, randomised controlled trial. PLoS Med. 16, e1002901 (2019).

233. Collotta, D. et al. Baricitinib counteracts metaflammation, thus protecting against diet-induced metabolic abnormalities in mice. Mol. Metab. 39, 101009 (2020).

234. Stanley, T. L. et al. TNF- $\alpha$ antagonism with etanercept decreases glucose and increases the proportion of high molecular weight adiponectin in obese subjects with features of the metabolic syndrome. J. Clin. Endocrinol. Metab. 96, E146-E150 (2011).

235. Gupta-Ganguli, M., Cox, K., Means, B., Gerling, I. \& Solomon, S. S. Does therapy with anti-TNF- $\alpha$ improve glucose tolerance and control in patients with type 2 diabetes? Diabetes Care 34, e121 (2011).

236. Solomon, D. H. et al. Association between diseasemodifying antirheumatic drugs and diabetes risk in patients with rheumatoid arthritis and psoriasis. JAMA 305, 2525-2531 (2011).

237. Burska, A. N., Sakthiswary, R. \& Sattar, N. Effects of tumour necrosis factor antagonists on insulin sensitivity/resistance in rheumatoid arthritis: a systematic review and meta-analysis. PLOS ONE 10 , e0128889 (2015).

238. Schacke, H., Docke, W. D. \& Asadullah, K. Mechanisms involved in the side effects of glucocorticoids. Pharmacol. Ther. 96, 23-43 (2002).

239. Hamming, I. et al. Tissue distribution of ACE2 protein the functional receptor for SARS coronavirus. A first step in understanding SARS pathogenesis. J. Pathol. 203, 631-637 (2004).

240. Nansen, A., Christensen, J. P., Marker, O. $\&$ Thomsen, A. R. Sensitization to lipopolysaccharide in mice with asymptomatic viral infection: role of T celldependent production of interferon-gamma. J. Infect. Dis. 176, 151-157 (1997).

241. Neu, U. \& Mainou, B. A. Virus interactions with bacteria: partners in the infectious dance. PLOS Pathog 16, e1008234 (2020).

242. Chen, G. et al. Clinical and immunological features of severe and moderate coronavirus disease 2019. J. Clin. Invest. 130, 2620-2629 (2020).

243. Teuwen, L. A., Geldhof, V., Pasut, A. \& Carmeliet, P. COVID-19: the vasculature unleashed. Nat. Rev. Immunol. 20, 389-391 (2020).

244. Pedersen, S. F. \& Ho, Y. C. SARS-CoV-2: a storm is raging. J. Clin. Invest. 130, 2202-2205 (2020).

245. Xu, Z. et al. Pathological findings of COVID-19 associated with acute respiratory distress syndrome Lancet Respir. Med. 8, 420-422 (2020).

246. Tian, S. et al. Pulmonary pathology of early-phase 2019 novel coronavirus (COVID-19) pneumonia in two patients with lung cancer. J. Thorac. Oncol. 15, 700-704 (2020)

247. Imai, Y. et al. Identification of oxidative stress and Toll-like receptor 4 signaling as a key pathway of acute lung injury. Cell 133, 235-249 (2008).

248. Chen, I. Y., Moriyama, M., Chang, M. F. \& Ichinohe, T. Severe acute respiratory syndrome coronavirus viroporin 3a activates the NLRP3 inflammasome. Front. Microbiol. 10, 50 (2019).

249. Kuba, K., Imai, Y. \& Penninger, J. M. Angiotensinconverting enzyme 2 in lung diseases. Curr. Opin. Pharmacol. 6, 271-276 (2006)

250. Tang, X. et al. Comparison of hospitalized patients with ARDS caused by COVID-19 and H1N1. Chest 158 195-205 (2020).

251. Vaduganathan, M. et al. Renin-angiotensin-aldosterone system inhibitors in patients with Covid-19. N. Engl. J. Med. 382, 1653-1659 (2020).

This article raises the concern that withdrawal of RAAS inhibitors might be harmful in certain high-risk patients with known or suspected COVID-19.

252. Luther, J. M. \& Brown, N. J. The renin-angiotensinaldosterone system and glucose homeostasis. Trends Pharmacol. Sci. 32, 734-739 (2011). 
253. Schwartz, S. S. et al. The time is right for a new classification system for diabetes: rationale and implications of the $\beta$-cell-centric classification schema. Diabetes Care 39, 179-186 (2016).

254. Imai, Y. et al. Angiotensin-converting enzyme 2 protects from severe acute lung failure. Nature $\mathbf{4 3 6}$ 112-116 (2005).

255. Kuba, K. et al. A crucial role of angiotensin converting enzyme 2 (ACE2) in SARS coronavirus-induced lung injury. Nat. Med. 11, 875-879 (2005).

256. Ranucci, M. et al. The procoagulant pattern of patients with COVID-19 acute respiratory distress syndrome. J. Thromb. Haemost. 18, 1747-1751 (2020).

257. Cummings, M. J. et al. Epidemiology, clinical course, and outcomes of critically ill adults with COVID-19 in New York city: a prospective cohort study. Lancet 395 1763-1770 (2020).

258. Roks, A. J. et al. Angiotensin-(1-7) is a modulator of the human renin-angiotensin system. Hypertension 34, 296-301 (1999).

259. Tom, B. de Vries, R. Saxena, P. R. \& Danser, A. H. Bradykinin potentiation by angiotensin-(1-7) and ACE inhibitors correlates with ACE C- and N-domain blockade. Hypertension 38, 95-99 (2001)
Author contributions

The authors contributed equally to all aspects of the article.

\section{Competing interests}

S.L. has been a member of advisory boards or has consulted with Merck, Sharp \& Dohme and NovoNordisk. S.L. has received grant support from AstraZeneca, Merck, Sharp \& Dohme and Astellas. S.L. has also served on the speakers bureau of AstraZeneca, Boehringer Ingelheim, Eli Lilly \& Co., Merck, Sharp \& Dohme, CKD Pharmaceutical and NovoNordisk. H.-S.K. has been a member of advisory boards or has consulted with Pfizer, Boehringer Ingelheim, Novartis, Daewoong Pharmaceutical, JW Pharmaceutical and NovoNordisk. H.-S.K. has received grant support from AstraZeneca. H.-S.K. has also served on the speakers' bureau of Eli Lilly \& Co., Merck, Sharp \& Dohme, YUHAN, Dong-A Pharmaceutical and NovoNordisk. M.A.N. has been member of advisory boards or has consulted with AstraZeneca, Boehringer Ingelheim, Eli Lilly \& Co., Fractyl, GlaxoSmithKline, Menarini/Berlin-Chemie, Merck, Sharp \& Dohme and NovoNordisk. M.A.N. has received grant support from AstraZeneca, Eli Lilly \& Co, Menarini/Berlin-Chemie, Merck Sharp \& Dohme, Novartis Pharma and NovoNordisk. M.A.N. has also served on the speakers' bureau of AstraZeneca Boehringer Ingelheim, Eli Lilly \& Co., Menarini/Berlin-Chemie,
Merck, Sharp \& Dohme, NovoNordisk and Sun Pharma. J.H.B. declares no competing interests.

\section{Peer review information}

Nature Reviews Endocrinology thanks M. Rizzo and the other, anonymous, reviewer(s) for their contribution to the peer review of this work.

\section{Publisher's note}

Springer Nature remains neutral with regard to jurisdictional claims in published maps and institutional affiliations.

\section{Supplementary information}

Supplementary information is available for this paper at https://doi.org/10.1038/s41574-020-00435-4.

\section{RELATED LINKS}

ClinicalTrials.gov database of COVID-19 interventional

studies: https://clinicaltrials.gov/ct2/results?type =

Intr\&cond =Covid-19

World Health Organization COVID-19 dashboard:

https://covid19.who.int/

(C) Springer Nature Limited 2020 